\title{
Shock Tube Radiation Measurements in Nitrogen
}

\author{
A. M. Brandis*† and B. A. Cruden*† \\ AMA Inc at NASA Ames Research Center, Mountain View, CA, 94035, USA
}

\begin{abstract}
Spectrally and spatially resolved radiance has been measured in the Electric Arc Shock Tube (EAST) facility, with the aim of improving fundamental understanding of high enthalpy flows in pure nitrogen. These tests provide data to inform models used for simulations of high speed flight in nitrogen rich atmospheres, such as Earth or Titan. The experiments presented in this paper cover conditions from approximately $6 \mathrm{~km} / \mathrm{s}$ to $11 \mathrm{~km} / \mathrm{s}$ at an initial pressure of 0.2 Torr. A wide range of physics, with different degrees of non-equilibrium and nitrogen dissociation, are covered. The EAST data are presented in different formats for analysis and comparisons. These formats include the spectral radiance at equilibrium (where appropriate), the spatial dependence of radiance over defined wavelength ranges and the mean non-equilibrium spectral radiance (the so-called "spectral non-equilibrium metric"). All the information needed to simulate each experimental trace, including free-stream conditions, shock time of arrival (i.e. x-t) relation, and the spectral and spatial resolution functions, are provided. Equilibrium radiation calculations are shown as a reference. It is the intention of this paper to motivate code comparisons benchmarked against this data set.
\end{abstract}

\section{Introduction}

$\mathrm{T}^{\mathrm{N}}$ recent years, the EAST facility at NASA Ames has been used to obtain validation data for radiative heating models. ${ }^{1-3}$ The shock tube produces high velocity gas flows with compositions and densities relevant to planetary entry. These conditions are achieved by creating a sudden pressure discontinuity which moves hypersonically into the gas in front of it, in the form of a normal shock wave. Because of the short time scales involved, the discontinuity does not have time to mix, but rather compresses the gas as it moves forward, much like a spacecraft will do to the atmosphere during planetary entry. This shock wave in EAST is therefore assumed to be analogous to the stagnation line behind the bow shock in an entry scenario. The radiating shock wave can be imaged as it passes through the shock tube, and separated into a wavelength spectrum via spectroscopy. This spectroscopic imaging of the shock is important as the radiation varies significantly with wavelength. The ability to predict and model both the non-equilibrium and equilibrium radiance depends upon understanding the mechanisms that produce different spectral features.

The shock tube data enables uncertainties to be quantified and to validate or update models used in simulation tools to predict radiative heating for re-entry vehicles. However, as kinetic models for atmospheric entry contain many inter-connected reaction mechanisms, difficulties can arise when trying to validate specific reaction rates. For example, with a standard air model used for re-entry analysis, e.g. Park $93,{ }^{4}$ there are 11 species and 21 reactions. By focusing on pure nitrogen, this test series aims to provide detailed information for a reduced system that isolates nitrogen specific mechanisms. In doing so, the relevant chemistry is greatly simplified as the number of collision partners is reduced and the complexity of various mechanisms, such as excitation, energy exchange and dissociation, is minimized. The reduced system now only requires 5 species and 4 reactions. These species include $\mathrm{N}, \mathrm{N}^{+}, \mathrm{N}_{2}, \mathrm{~N}_{2}^{+}$and $\mathrm{e}^{-}$with the following four reactions:

$$
\begin{gathered}
N_{2}+M \Longleftrightarrow N+N+M \\
N+e^{-} \Longleftrightarrow N^{+}+e^{-}+e^{-}
\end{gathered}
$$

*Senior Research Scientist, Aerothermodynamics Branch, and Associate Fellow AIAA.

†Contact: aaron.m.brandis@nasa.gov brett.a.cruden@nasa.gov 


$$
\begin{gathered}
N+N \Longleftrightarrow N_{2}^{+}+e^{-} \\
N^{+}+N_{2} \Longleftrightarrow N_{2}^{+}+N
\end{gathered}
$$

This allows for simpler analysis to infer or extract fundamental chemistry results from the experiment when testing in pure $\mathrm{N}_{2}$ compared to air. The data presented in this paper can be used to validate models relevant to vibrational relaxation, non-equilibrium state population models and partner specific dissociation. For example, with regards to partner specific dissociation, due to the range of velocity conditions tested during the campaign, there will be shots where dissociation is dominated by collisions with molecular nitrogen (lower speed conditions) and shots where dissociation is dominated by atomic nitrogen (higher speed conditions). This is an area of research with substantial fundamental calculation and simulation efforts in recent years, ${ }^{5-8}$ but validation data has been lacking. This dataset thus provides the capability to validate a wide range of physics and chemistry models and to be used for experimental comparisons.

\section{Description of the EAST Facility}

The EAST facility at NASA Ames Research Center was developed to simulate high-enthalpy, real gas phenomena encountered by hypersonic vehicles entering planetary atmospheres. Experiments are performed to match flow parameters relevant to flight, such as velocity, static pressure, and atmospheric composition. EAST has the capability of producing super-orbital shock speeds using an electric arc driver with a driven tube diameter of $10.16 \mathrm{~cm}^{9,10}$ The region of valid test gas is located between the shock front and the contact surface that separates the driver and driven gases. The test duration is defined as the axial distance between these two points divided by the local shock velocity. The characteristics of the EAST arc driver result in test durations of approximately $4-10 \mu \mathrm{s}$. Though short, this test duration is often sufficient to capture the non-equilibrium radiation pulse and, for the higher speed / higher pressure conditions, the decay to equilibrium. Charge Coupled Devices (CCDs), attached to spectrometers, are activated when the shocked gas arrives at the test section and the spectral and spatial emission of the gas are measured. EAST utilizes four spectrometers per shot, each associated with four different wavelength ranges. These cameras are referred to as: VUV $(\sim 120-215 \mathrm{~nm})$, UV/Vis $(\sim 190 \mathrm{~nm}-500 \mathrm{~nm})$, Vis/NIR $(\sim 480 \mathrm{~nm}-900 \mathrm{~nm})$, and $\mathrm{IR}(\sim 700 \mathrm{~nm}-1650 \mathrm{~nm})$.

\section{II.A. Test Conditions}

Figure 1 shows a comparison of pure nitrogen EAST testing conditions, known as Test 62, with various flight missions that re-entered Earth's atmosphere, proposed Mars return missions and a candidate Titan entry. The nominal test conditions for Test 62 were chosen to span a variety of trajectories re-entering Earth's atmosphere, for sample return, highly elliptical orbits or for lunar return. These conditions correspond to a shock speed range of approximately $6 \mathrm{~km} / \mathrm{s}$ to $11 \mathrm{~km} / \mathrm{s}$ and a free stream pressure of 0.2 Torr. The test gas composition for all experiments in this campaign was $100 \% \mathrm{~N}_{2}$. Data from these tests may be obtained by contacting the authors or visiting the EAST data storage website:

(https://data.nasa.gov/docs/datasets/aerothermodynamics/EAST/index.html).

\section{Summary of Codes}

In order to obtain a better understanding of the level of equilibration reached in relevant experiments, data are compared to radiation simulations with NEQAIR based on equilibrium calculations from CEA. This section will provide a brief overview of these codes for reference. Results from CEA/NEQAIR calculations can be used to assess the equilibrium quality of the steady-state region of EAST tests.

\section{III.A. CEA}

Chemical Equilibrium with Applications ( $\mathrm{CEA})^{16}$ is a code that calculates chemical equilibrium compositions from any set of reactants and determines thermodynamic and transport properties for the product mixture. 


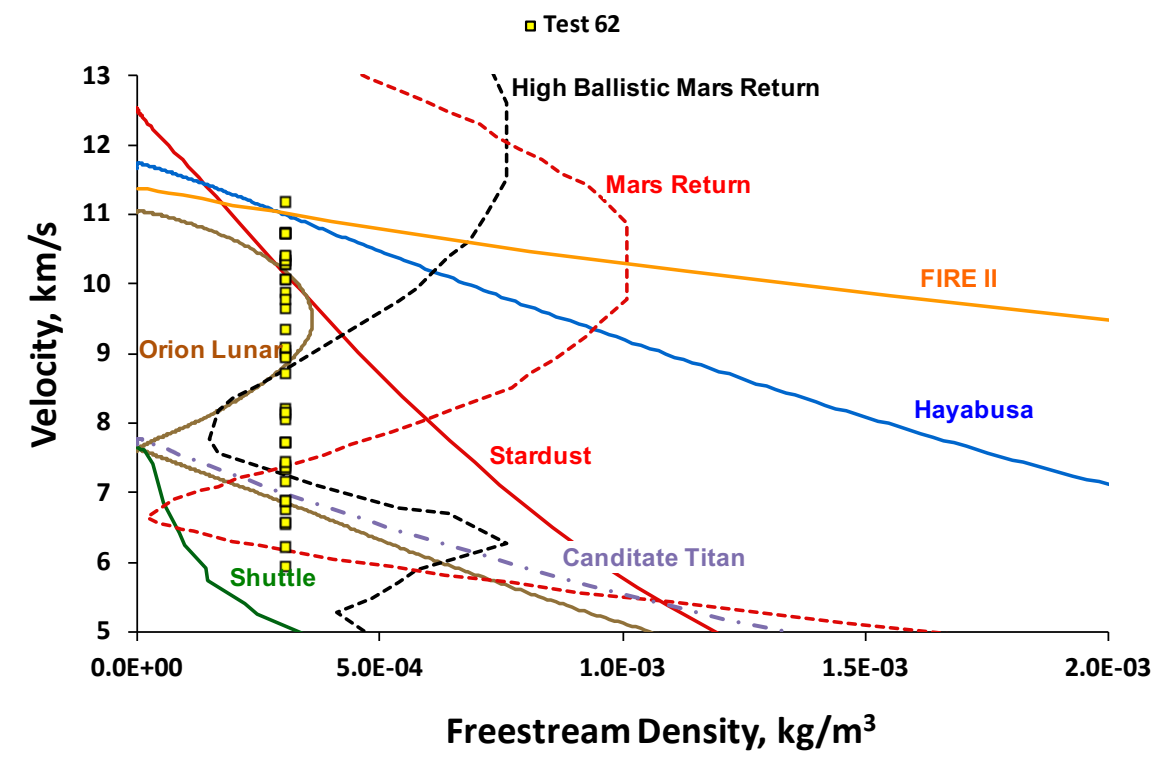

Figure 1. Comparison of EAST Test 62 conditions to various flight missions that re-entered Earth's atmosphere, proposed Mars return missions and a candidate Titan entry.

CEA covers a wide range of applications including theoretical rocket performance, detonations, and shocktubes. CEA provides the equilibrium species number densities and shock layer temperatures NEQAIR needs to calculate radiation.

\section{III.B. NEQAIR}

Non-EQuilibrium AIr Radiation (NEQAIR) is a line-by-line radiation code which computes spontaneous emission, absorption and stimulated emission due to transitions between various energy states of chemical species along a line-of-sight. ${ }^{11}$ Individual electronic transitions are considered for atoms and molecules, with the molecular band systems being resolved for each rovibronic line. Since the report of Whiting et al., ${ }^{11}$ numerous updates have been incorporated into NEQAIR, such as: using the latest version of the NIST atomic database (version 5.0), ${ }^{12}$ using the bound-free cross sections from $\mathrm{TOPbase}^{13}$ incorporating the $\mathrm{CO}_{2}$ database from CDSD-4000, ${ }^{14}$ parallelization and improvements to the mechanics of the Quasi Steady State (QSS) model. The current release version of NEQAIR is known as v14.0. ${ }^{15}$

\section{Equilibrium Radiance and Non-equilibrium Metric Definition}

The equilibrium radiance level is determined by analyzing the spatial radiance integrated over a specified wavelength range. The equilibrium level is then extracted from a region where the radiance reaches steady state, and before the arrival of any driver contamination to end the test. Further details regarding identifying equilibrium radiance from EAST experiments is provided in Ref. 17. For non-equilibrium regions of EAST experiments, a previously defined non-equilibrium metric ${ }^{18}$ is used to provide non-equilibrium spectral data, to analyze many non-equilibrium data-sets simultaneously and identify benchmark shots. This metric is computed by integrating the radiance within $\pm 2 \mathrm{~cm}$ of the shock front, as shown by the red lines in Fig. 2 , and then normalizing by the shock tube diameter. Computing the metric in this manner has been suggested as a more robust way to conduct a comparison as opposed to using other parameters, such as the peak intensity, since the comparisons are then not bound to experimental resolution limitations such as gate opening times and spatial smearing due to shock movement. Under optically thin conditions, this integral will represent the radiance as observed parallel to the direction of the shock. Under optically thick conditions, however, this integral is not related to such a physical quantity and is simply a way of comparing data corresponding to a given optical path-length/shock tube diameter. For most cases, the shock front is defined as the location of peak radiance. For higher speed/pressure shots that do not over-shoot equilibrium, the location of the shock front is chosen to be the inflection in the radiance as equilibrium is reached. For some cases higher speed 
cases in the IR, where there is significant spatial smearing and a small amount of non-equilibrium radiance, the non-equilibrium metric cannot be reasonably defined.

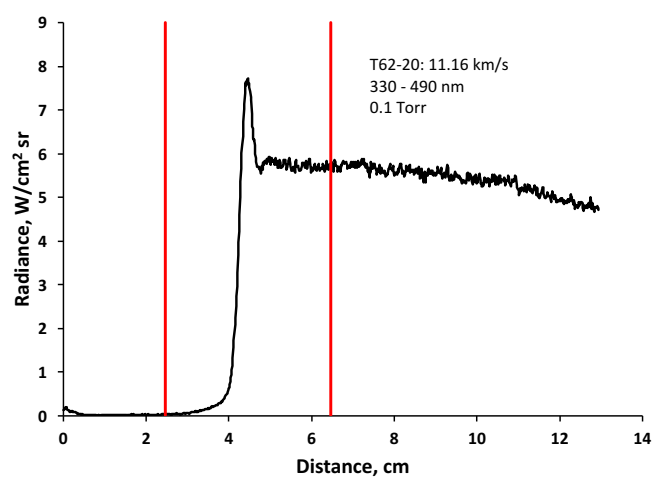

Figure 2. Example of the absolute non-equilibrium radiance metric used in this work: Integrating the intensity from $2 \mathrm{~cm}$ before the shock peak until $2 \mathrm{~cm}$ after the shock peak.

\section{Experimental Data}

The goal of the experimental campaign is to provide benchmark quality data for validation studies. To that end, benchmark experiments are identified as those experiments consistent in both non-equilibrium and equilibrium and, in most cases, show good experimental characteristics across all four cameras of a given experiment. Furthermore, in order to capture the changing physics with shock speed, benchmark shots have been chosen at increments of approximately 0.5 to $1 \mathrm{~km} / \mathrm{s}$. The spatial radiance integrated over defined wavelength ranges, the steady state spectral radiance (where appropriate) and the non-equilibrium metric applied to spectral radiance (where appropriate) is provided for these benchmark experiments.

This section will first compare the equilibrium radiance integrated over wavelength ranges relevant to each camera from each shot to check for experimental consistency. Furthermore, comparisons are made with CEA/NEQAIR calculations to provide an assessment for the level of agreement with theoretical equilibrium radiance. The equilibrium radiance is presented in Fig. 3. For low speed cases in the VUV, less the approximately $7.5 \mathrm{~km} / \mathrm{s}$, subtracting the dark counts from an experiment with very small radiance, often causes the VUV "steady state" radiance to be negative. Therefore these lower velocity cases are not shown in Figs. 3(a) and 3(b). The non-equilibrium metric is also calculated for each camera for each shot to highlight experimental consistency in the non-equilibrium regime. The non-equilibrium metric data is presented in Fig. 4. In both cases, the equilibrium radiance or non-equilibrium metric is calculated as a function of velocity for a specified wavelength range covering the VUV through IR. The benchmark experiments are highlighted in each figure with a red circle. For determining benchmark data, the equilibrium radiance is given greater weighting at the higher speed conditions, while the non-equilibrium metric is given greater weighting at the lower speed conditions. 


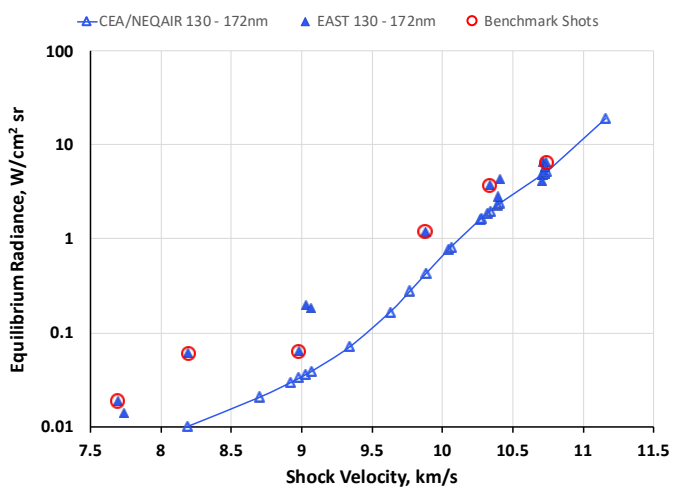

(a) 130 to $172 \mathrm{~nm}$

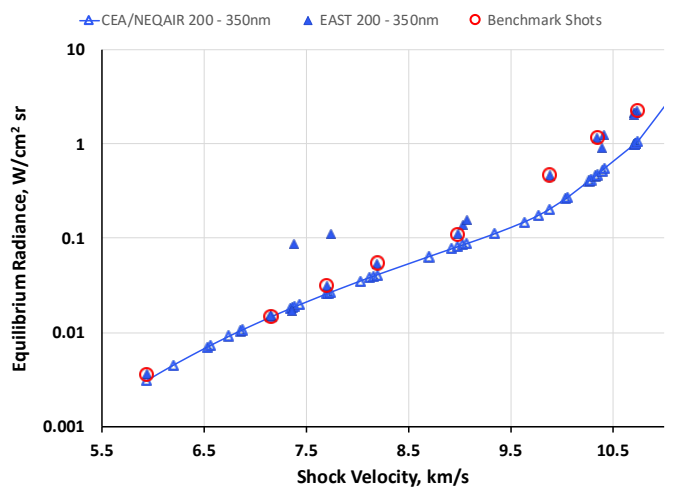

(c) 200 to $350 \mathrm{~nm}$

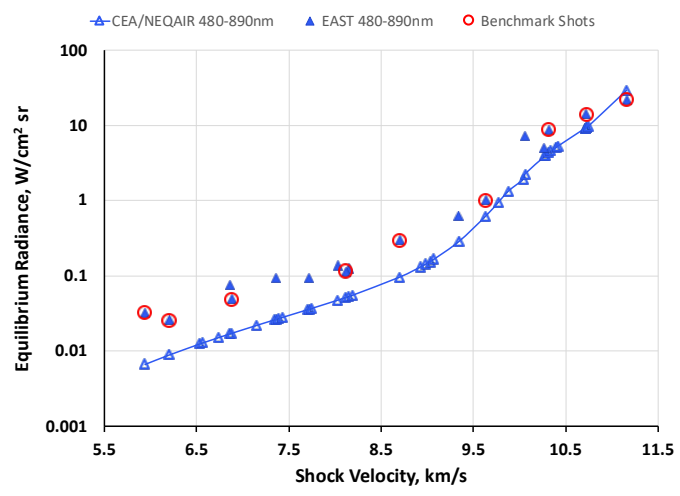

(e) 480 to $890 \mathrm{~nm}$

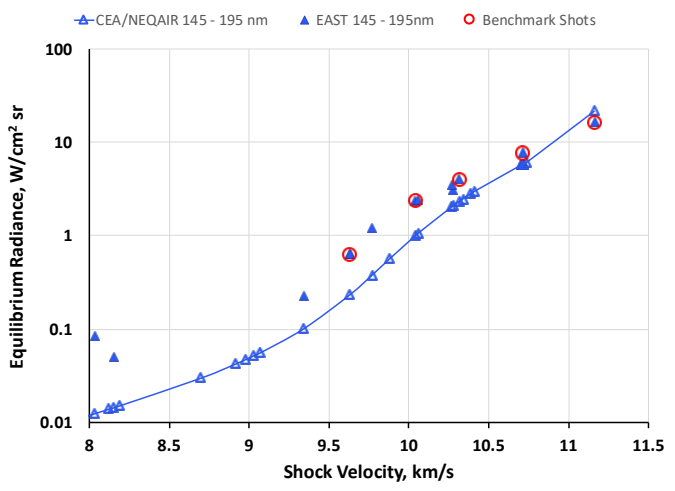

(b) 145 to $195 \mathrm{~nm}$

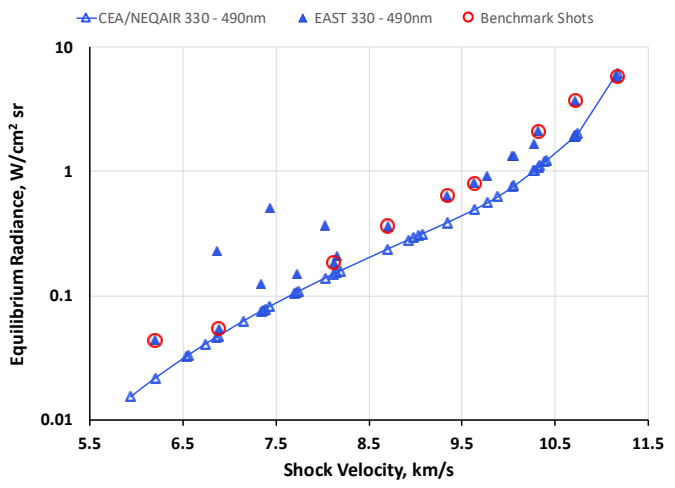

(d) 330 to $490 \mathrm{~nm}$

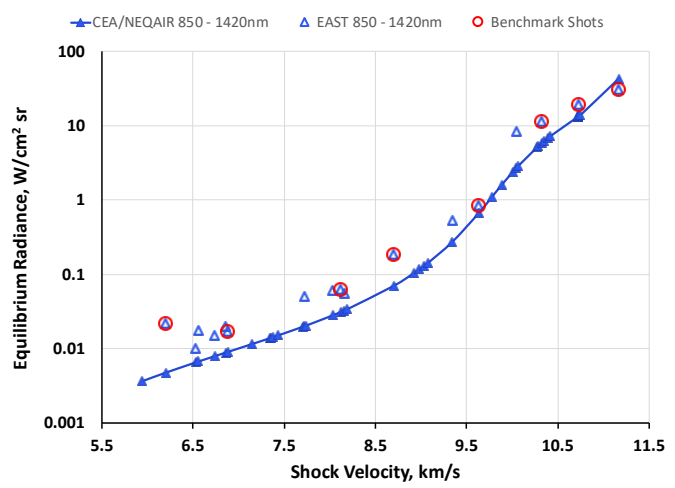

(f) 850 to $1420 \mathrm{~nm}$

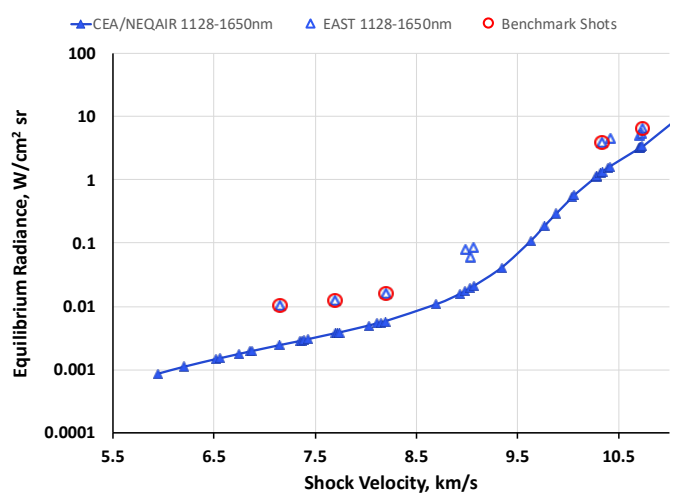

(g) 1128 to $1650 \mathrm{~nm}$

Figure 3. Equilibrium Radiance for Test 62 data at 0.2 Torr. Circled points are the designated benchmark experiments. 


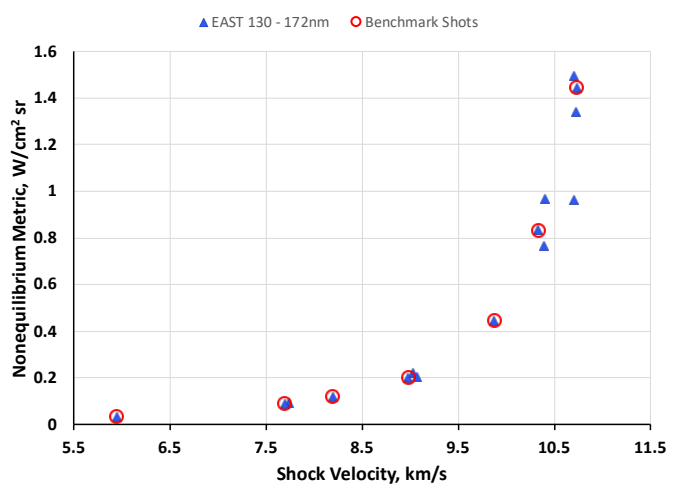

(a) 130 to $172 \mathrm{~nm}$

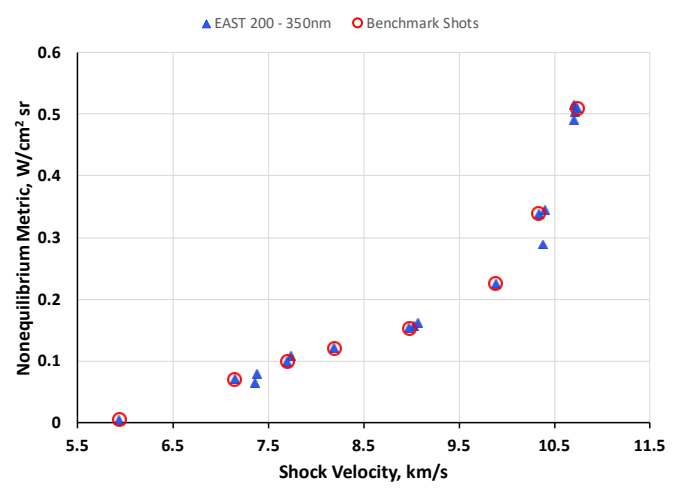

(c) 200 to $350 \mathrm{~nm}$

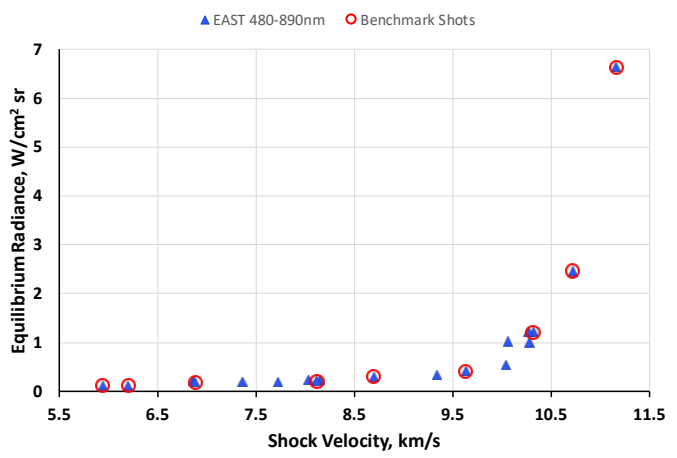

(e) 480 to $890 \mathrm{~nm}$

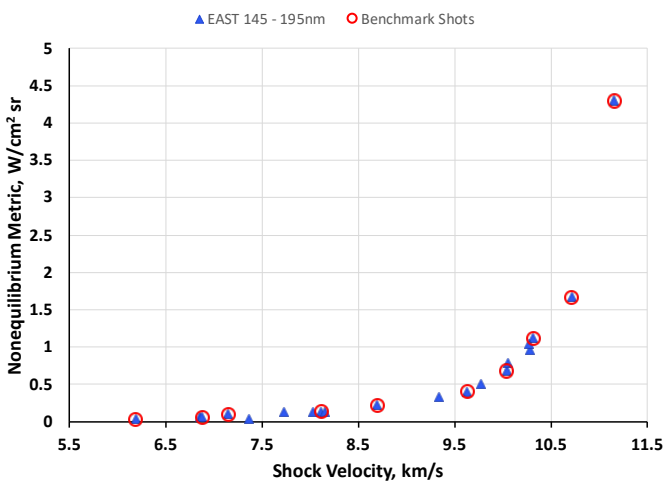

(b) 145 to $195 \mathrm{~nm}$

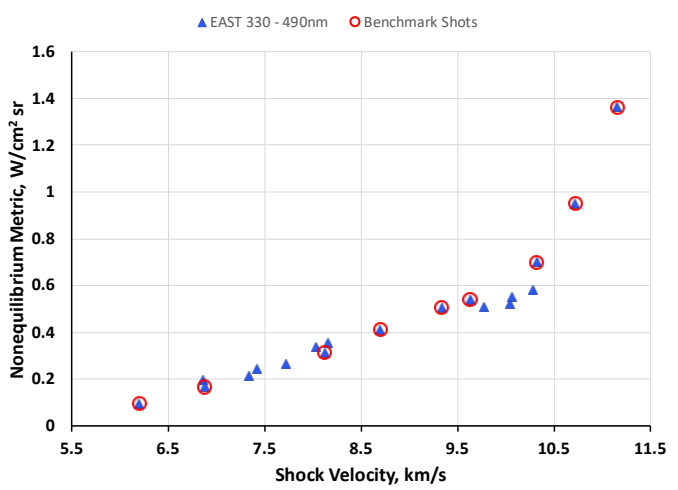

(d) 330 to $490 \mathrm{~nm}$

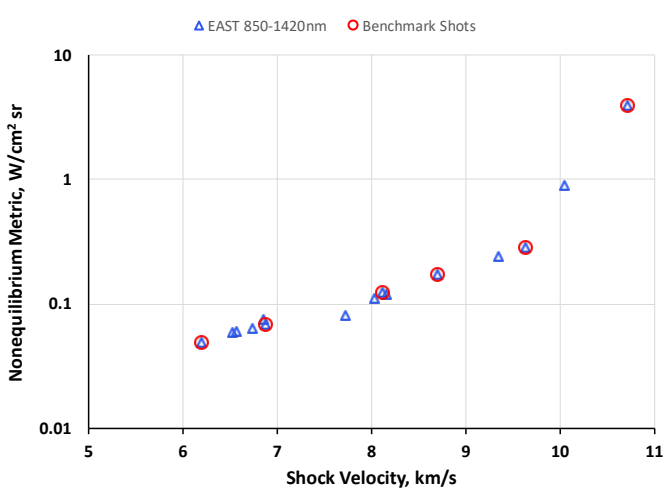

(f) 850 to $1420 \mathrm{~nm}$

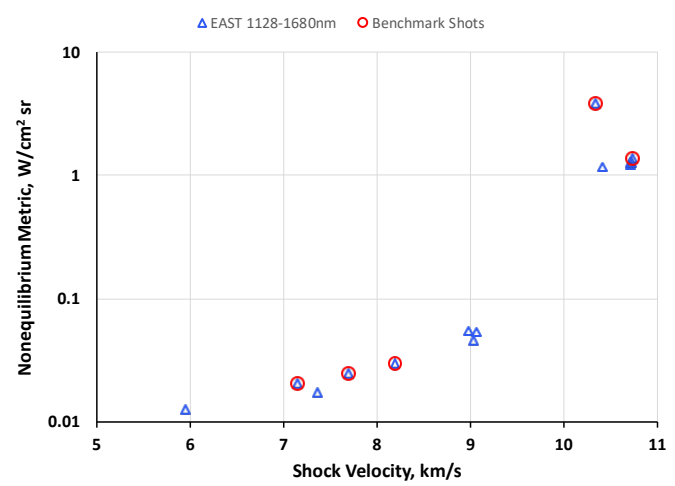

(g) 1128 to $1650 \mathrm{~nm}$

Figure 4. Non-equilibrium Metric for Test 62 data at 0.2 Torr. Circled points are the designated benchmark experiments. 


\section{V.A. Benchmark Data}

The Test 62 benchmark shots identified are shown in Table 1 with spectral ranges highlighted for the best quality data for each shot. Care was taken to assign the benchmark data label to shots that showed good experimental characteristics and consistency with the non-equilibrium metric and equilibrium radiance across all cameras. Furthermore, data was highlighted at approximately regular intervals to capture the change in relevant physics from lower speeds $(\approx 6 \mathrm{~km} / \mathrm{s})$ to higher speeds $(\approx 11 \mathrm{~km} / \mathrm{s})$. With the benchmark data selected, the spatial and non-equilibrium / equilibrium spectral radiance for each shot is detailed in the following three subsections.

Table 1. Benchmark Test 62 EAST Shots at 0.2 Torr.

\begin{tabular}{|c|c|c|c|c|c|c|c|c|}
\hline \multirow{2}{*}{$\begin{array}{c}\text { Shot } \\
\#\end{array}$} & \multirow{2}{*}{$\begin{array}{c}\text { Shock Speed, } \\
\mathrm{km} / \mathrm{s}\end{array}$} & \multicolumn{2}{|c|}{ VUV, nm } & \multicolumn{2}{|c|}{ UV, nm } & \multirow{2}{*}{$\begin{array}{c}\text { Vis/NIR, nm } \\
480-890\end{array}$} & \multicolumn{2}{|c|}{$\mathrm{IR}, \mathbf{n m}$} \\
\hline & & 130-172 & 145-195 & $200-350$ & $330-490$ & & $850-1420$ & $1128-1650$ \\
\hline 42 & 5.94 & & & $\mathrm{X}$ & & $\mathrm{X}$ & & \\
\hline 41 & 6.20 & & & & $\mathrm{X}$ & $\mathrm{X}$ & $\mathrm{X}$ & \\
\hline 40 & 6.88 & & $\mathrm{X}$ & & $\mathrm{X}$ & $\mathrm{X}$ & $\mathrm{X}$ & \\
\hline 37 & 7.15 & $\mathrm{X}$ & & $\mathrm{X}$ & & & & $\mathrm{X}$ \\
\hline 16 & 7.70 & $\mathrm{X}$ & & $\mathrm{X}$ & & & & $\mathrm{X}$ \\
\hline 13 & 8.12 & & $\mathrm{X}$ & & $\mathrm{X}$ & $\mathrm{X}$ & $\mathrm{X}$ & \\
\hline 15 & 8.19 & $\mathrm{X}$ & & $\mathrm{X}$ & & & & $\mathrm{X}$ \\
\hline 6 & 8.70 & & $\mathrm{X}$ & & $\mathrm{X}$ & $\mathrm{X}$ & $\mathrm{X}$ & \\
\hline 9 & 8.98 & $\mathrm{X}$ & & $\mathrm{X}$ & & & & \\
\hline 5 & 9.63 & & $\mathrm{X}$ & & $\mathrm{X}$ & $\mathrm{X}$ & $\mathrm{X}$ & \\
\hline 4 & 9.88 & $\mathrm{X}$ & & $\mathrm{X}$ & & & & $\mathrm{X}$ \\
\hline 2 & 10.04 & & $\mathrm{X}$ & & $\mathrm{X}$ & & & \\
\hline 19 & 10.32 & & $\mathrm{X}$ & & $\mathrm{X}$ & $\mathrm{X}$ & $\mathrm{X}$ & \\
\hline 29 & 10.34 & $\mathrm{X}$ & & $\mathrm{X}$ & & & & $\mathrm{X}$ \\
\hline 21 & 10.72 & & $\mathrm{X}$ & & $\mathrm{X}$ & $\mathrm{X}$ & $\mathrm{X}$ & \\
\hline 23 & 10.74 & $\mathrm{X}$ & & $\mathrm{X}$ & & & & $\mathrm{X}$ \\
\hline 20 & 11.16 & & $\mathrm{X}$ & & $\mathrm{X}$ & $\mathrm{X}$ & $\mathrm{X}$ & \\
\hline
\end{tabular}




\section{V.B. Spatial Radiance}

This section details the spatial radiance for all the benchmark shots. In each set of figures, Fig. (a) shows the lower velocity experiments (generally from 6 to $9 \mathrm{~km} / \mathrm{s}$ ) and Fig. (b) shows the higher velocity experiments (generally from 9 to $11 \mathrm{~km} / \mathrm{s}$ ). The figures are shown for the VUV (Figs. 5 \& 6), UV/Vis (Figs. 7 \& 8), Vis/NIR (Fig. 9) and IR (Figs. 10 \& 11) spectral ranges. The VUV spectral range at lower speed is dominated by the non-equilibrium pulse, decaying to a radiance close to the noise floor that can be measured on the CCD (up until approximately $9.5 \mathrm{~km} / \mathrm{s}$ ). It is not until shot T62-4 at $9.88 \mathrm{~km} / \mathrm{s}$ for the $130-172 \mathrm{~nm}$ range and until shot T62-5: $9.63 \mathrm{~km} / \mathrm{s}$ for the $145-195 \mathrm{~nm}$ range that an appreciable equilibrium radiance is observed. As the velocity increases, the relative level of equilibrium increases (as to be expected), so much so that by the second highest velocity measured $(10.74 \mathrm{~km} / \mathrm{s})$, the equilibrium radiance exceeds the non-equilibrium peak and at the highest velocity $(11.16 \mathrm{~km} / \mathrm{s})$ the radiance equilibrates fast enough that no non-equilibrium pulse is observed.

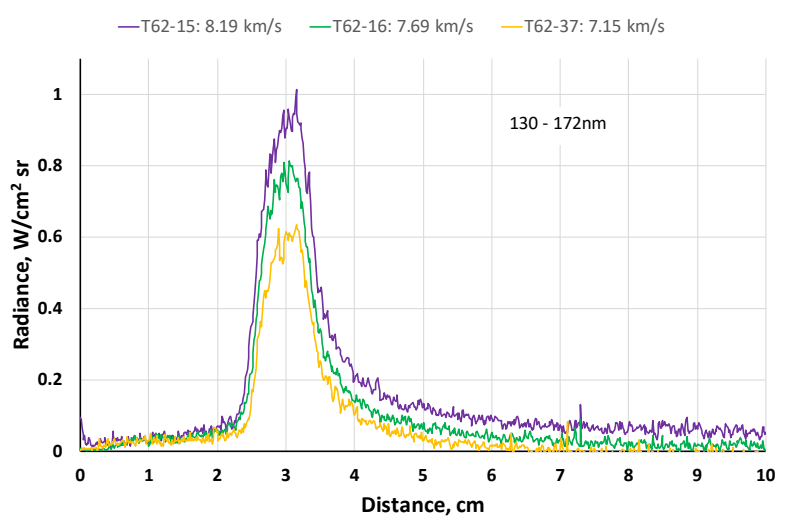

(a) Lower velocities

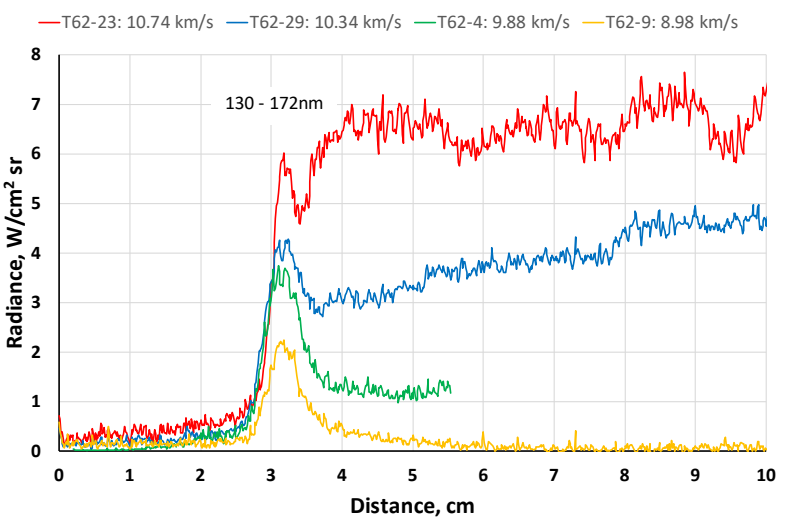

(b) Higher velocities

Figure 5. Test 62 data at 0.2 Torr integrated from 130 to $172 \mathrm{~nm}$.

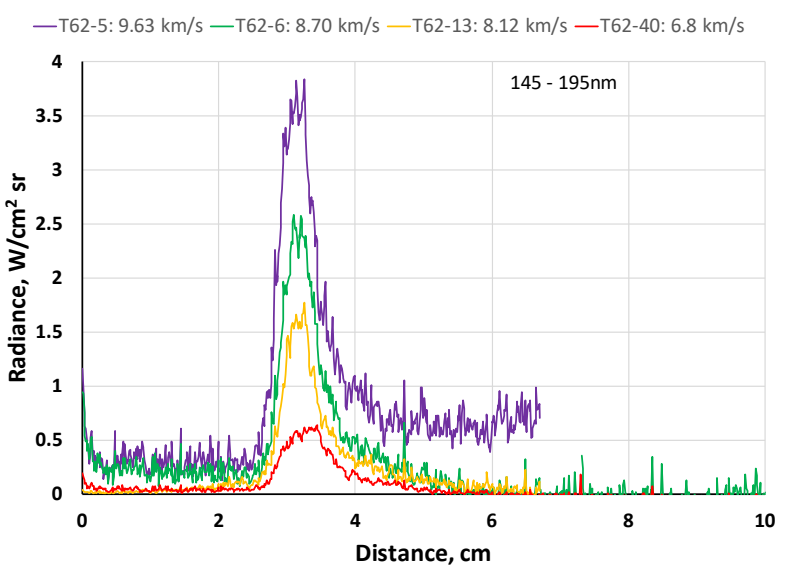

(a) Lower velocities

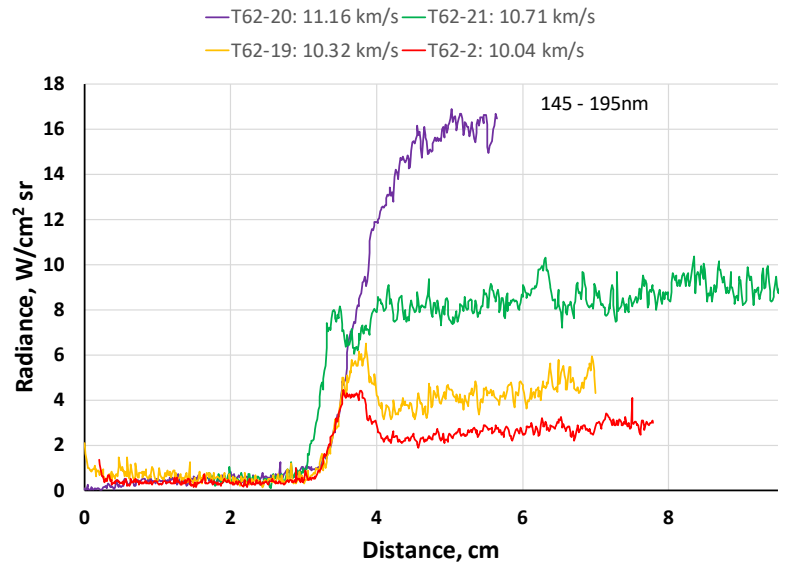

(b) Higher velocities

Figure 6. Test 62 data at 0.2 Torr integrated from 145 to $195 \mathrm{~nm}$. SHOT 21 is 10.72!!! 
As with the VUV spectral region, the lower speed UV shots are dominated by the non-equilibrium pulse. However, the level of equilibrium radiance becomes more significant at a lower velocity, around $8.12 \mathrm{~km} / \mathrm{s}$. In this context, significant equilibrium represents that a steady state radiance has been achieved above the noise floor within the $12 \mathrm{~cm}$ that can be imaged in EAST. It is interesting to note that for the higher velocity cases $(9.88$ to $11.16 \mathrm{~km} / \mathrm{s})$, the non-equilibrium pulse is nearly identical in both magnitude and shape for all cases, followed by relaxation to very different equilibrium levels. This indicates that for these conditions, the decreasing $\mathrm{N}_{2} / \mathrm{N}_{2}^{+}$molecular number density is off-setting the increased temperature to provide an equivalent magnitude of non-equilibrium radiance. The relaxation to equilibrium is different for each case, with the steady state atomic radiation significantly different in each case as is expected.

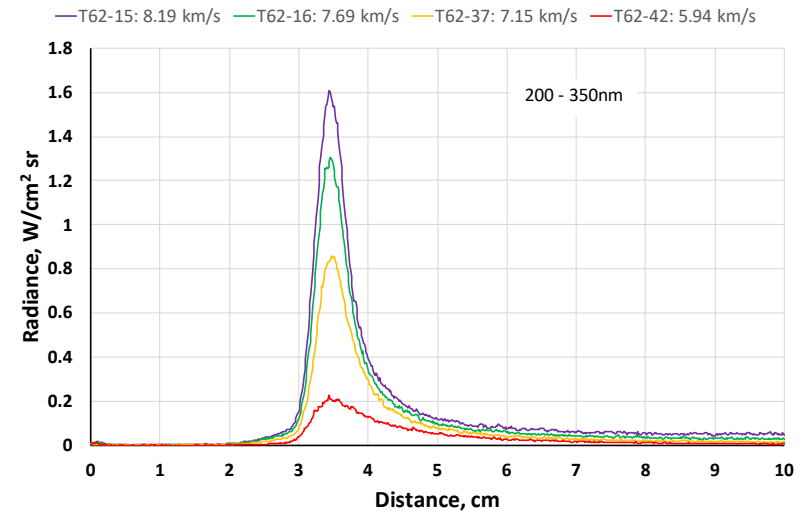

(a) Lower velocities

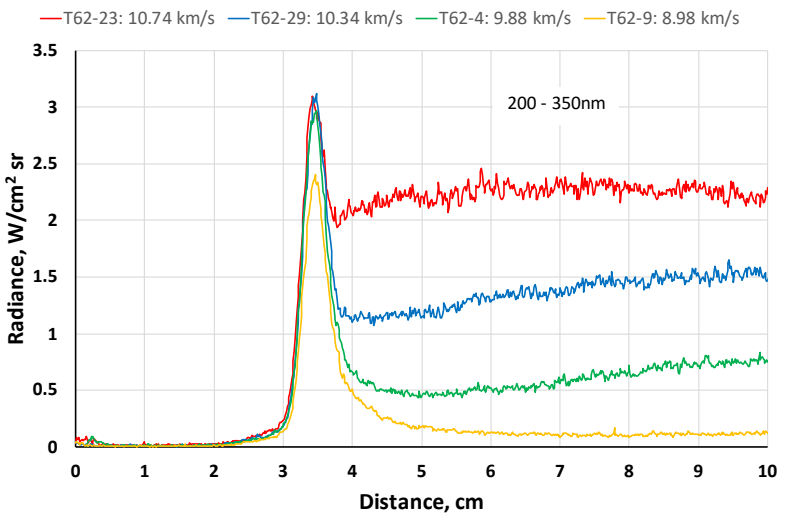

(b) Higher velocities

Figure 7. Test 62 data at 0.2 Torr integrated from 200 to $350 \mathrm{~nm}$.

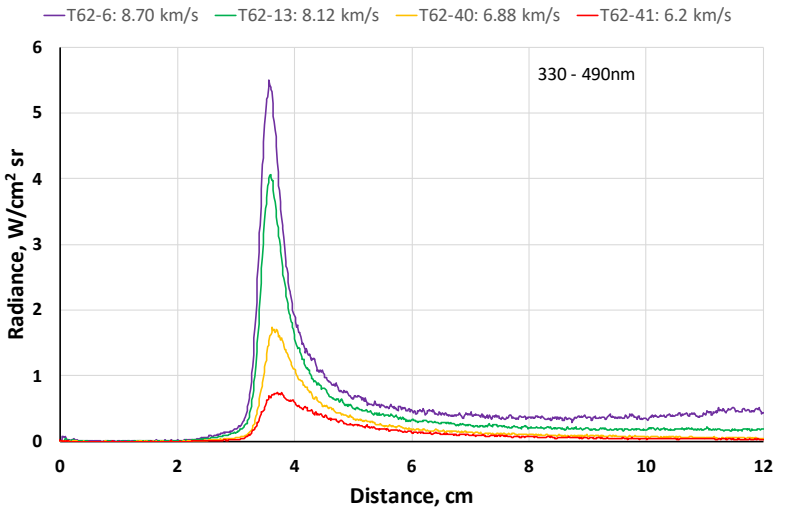

(a) Lower velocities

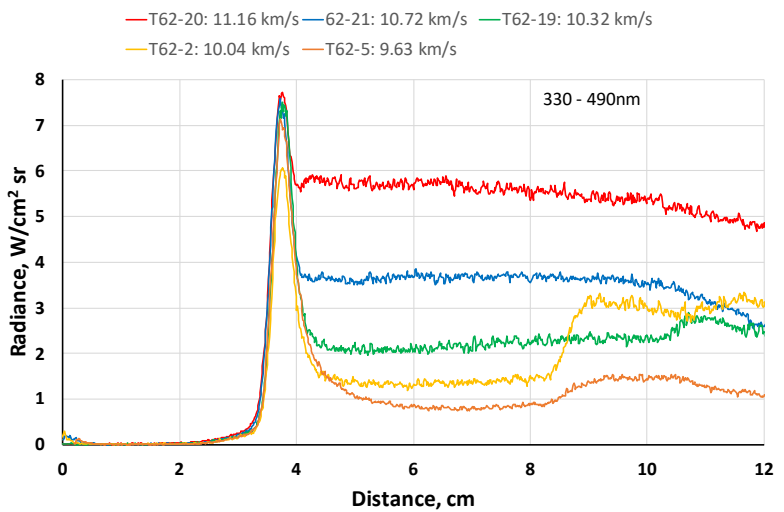

(b) Higher velocities

Figure 8. Test 62 data at 0.2 Torr integrated from 330 to $490 \mathrm{~nm}$.

The Vis/NIR through IR spectral regions show similar trends, with the lower velocity shots being dominated by non-equilibrium and then equilibrium dominating at higher velocity, from approximately $10.3 \mathrm{~km} / \mathrm{s}$. Due to relatively longer exposure times on the IR camera, it might be beyond the spatial resolution of the camera to identify non-equilibrium radiation at conditions where non-equilibrium effects are still notionally significant, as could be the cases above $10.3 \mathrm{~km} / \mathrm{s}$ presented in Figs. 10(b) and 11(b). 


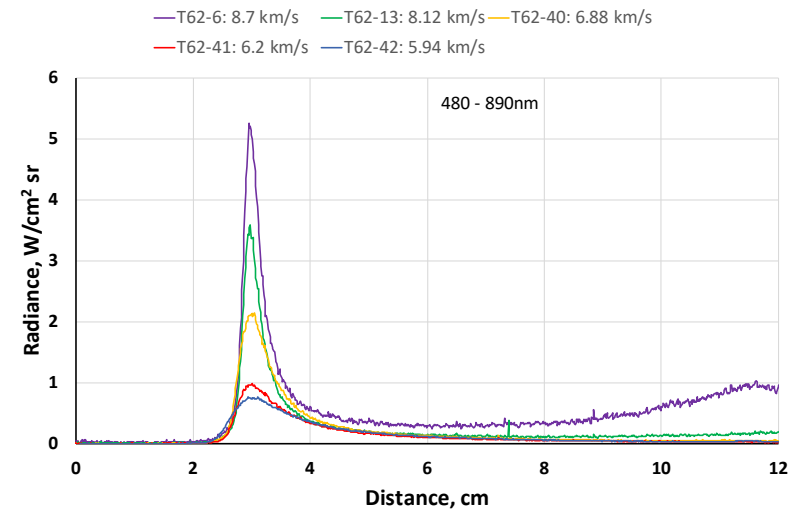

(a) Lower velocities

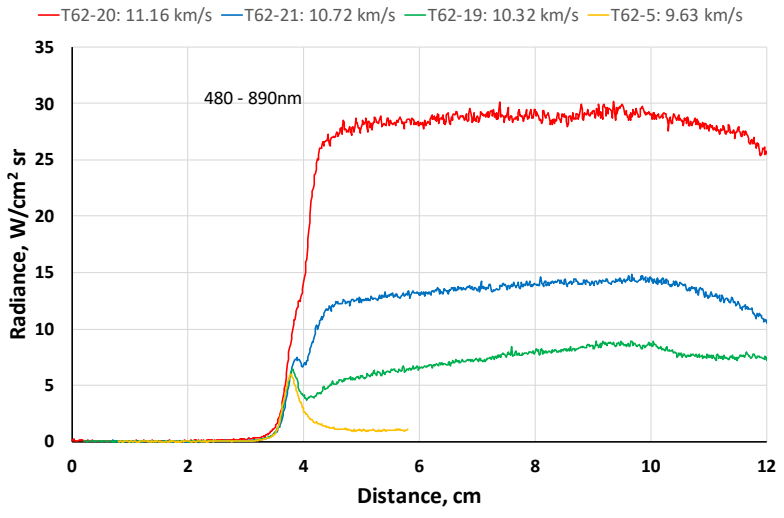

(b) Higher velocities

Figure 9. Test 62 data at 0.2 Torr integrated from 480 to $890 \mathrm{~nm}$.

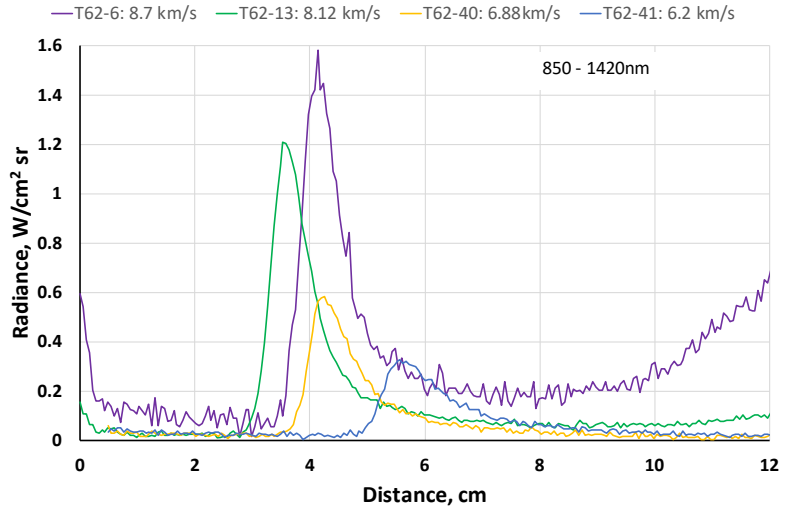

(a) Lower velocities

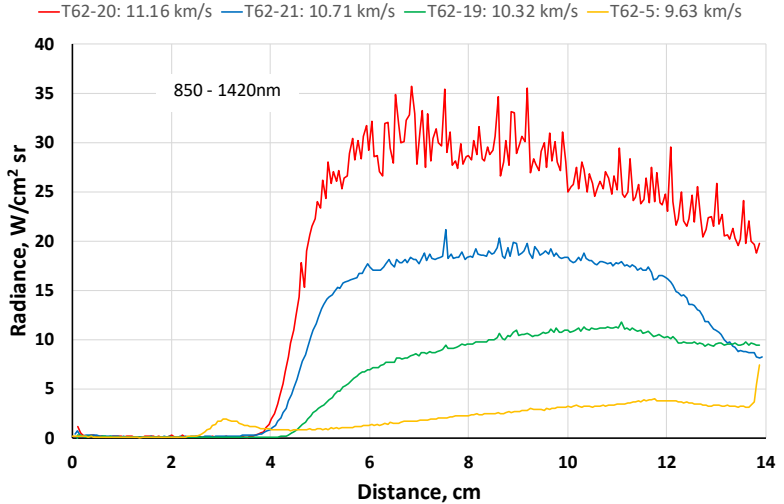

(b) Higher velocities

Figure 10. Test 62 data at 0.2 Torr integrated from 850 to $1420 \mathrm{~nm}$.

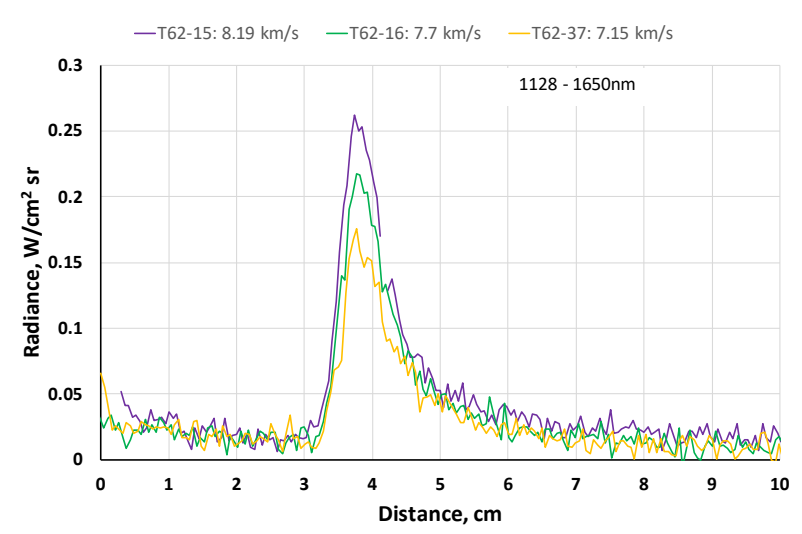

(a) Lower velocities

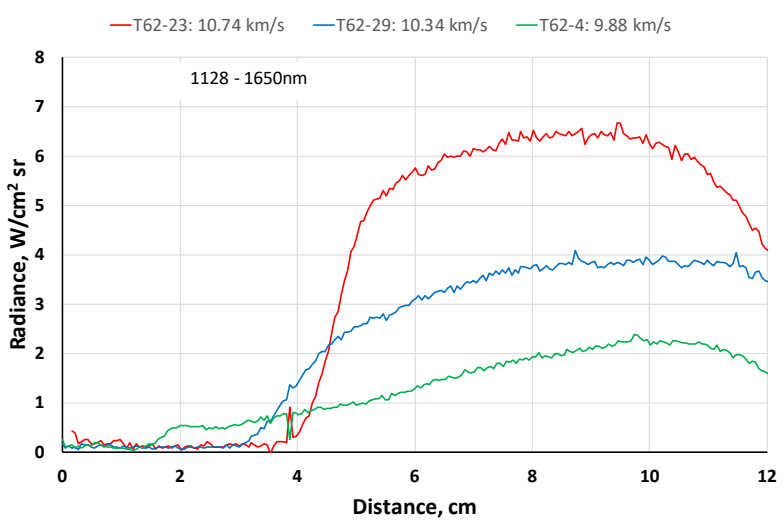

(b) Higher velocities

Figure 11. Test 62 data at 0.2 Torr integrated from 1128 to $1650 \mathrm{~nm}$. 
For utilization of this work as code validation data, matching the spatial radiance (integrated over discrete wavelength regions) is not sufficient for thorough model validation. In order to confirm that a model is matching the spatial radiance for the correct reasons, the spectral features need to be examined in both non-equilibrium and equilibrium. These results are shown in the following sections.

\section{V.C. Steady State Spectral Radiance}

Figure 12 shows the steady state, or equilibrium, spectral radiance extracted for the VUV through IR spectral regions from shots that show the best equilibrium characteristics from their spatial radiance traces. These experiments tend to be higher speed shots, as the time needed to reach equilibrium is shorter due to the increased number of particle collisions and the signal level is large enough to exceed the camera noise floor. At the lowest speeds tested, there is often not enough test time, or even length from the optical access, for the flow to reach equilibrium. Furthermore, for certain wavelength ranges and conditions, the signalto-noise ration at the equilibrium radiance level can be quite low. The equilibrium spectrum is dominated by atomic nitrogen radiation, with some continuum and molecular radiation also being significant in the $\mathrm{UV} / \mathrm{Vis}$ spectral regions. 


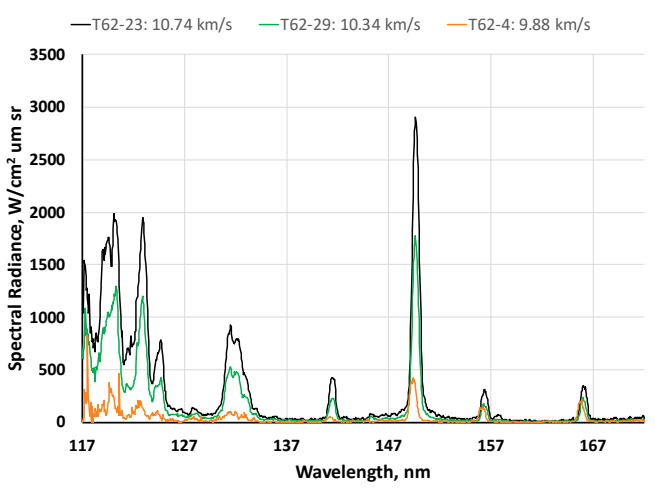

(a) 130 to $172 \mathrm{~nm}$

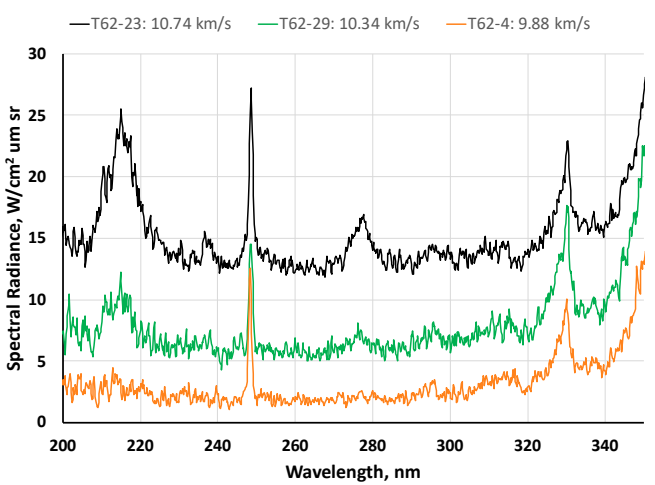

(c) 200 to $350 \mathrm{~nm}$

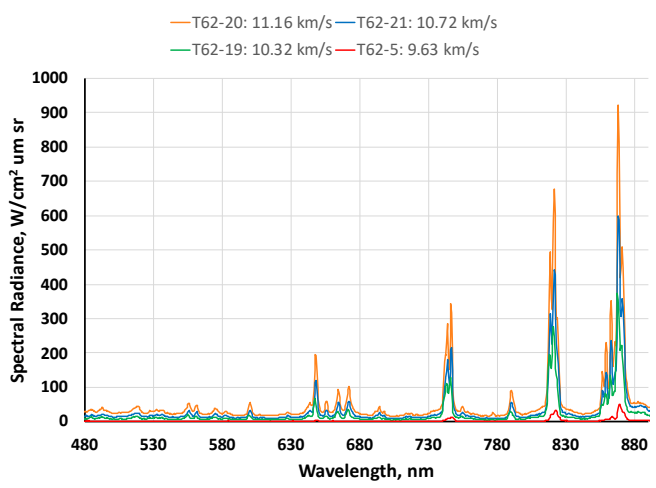

(e) 480 to $890 \mathrm{~nm}$

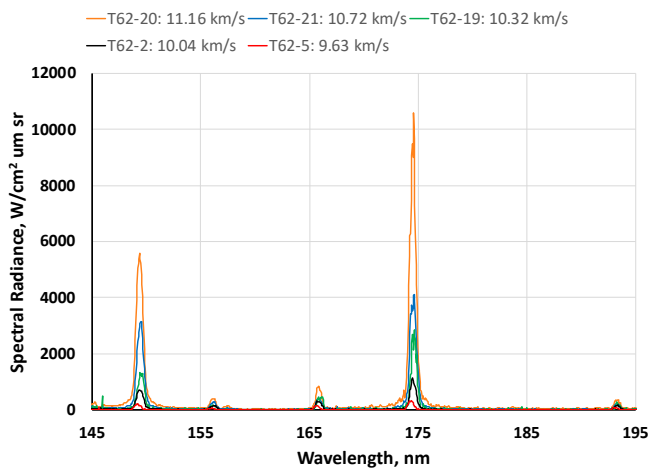

(b) 145 to $195 \mathrm{~nm}$

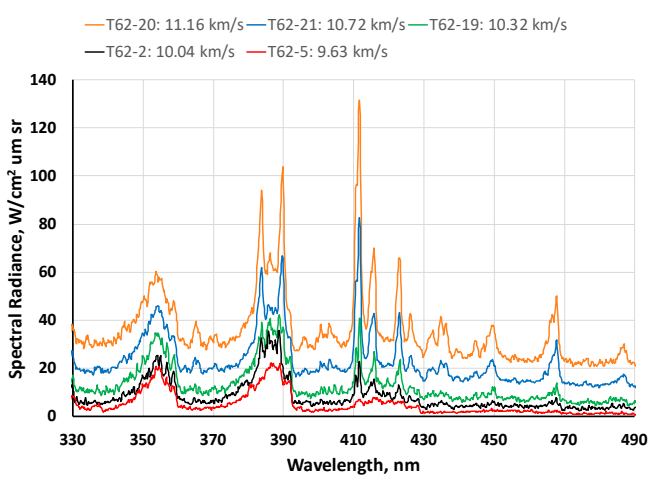

(d) 330 to $490 \mathrm{~nm}$

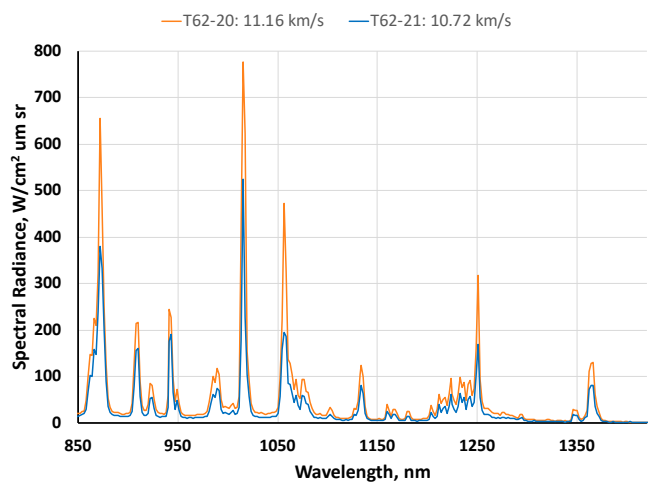

(f) 850 to $1420 \mathrm{~nm}$

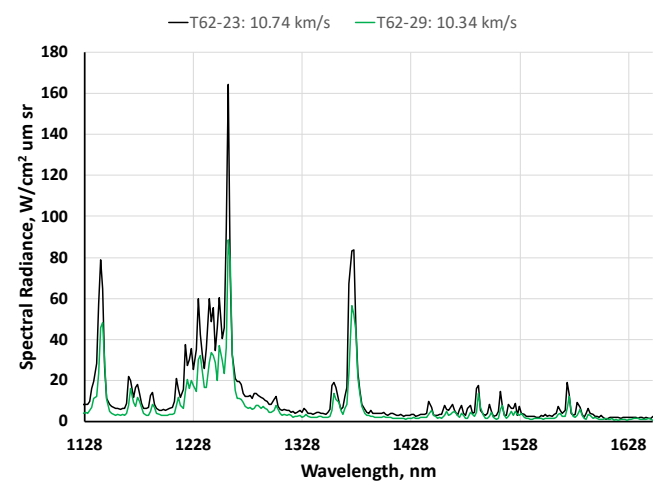

(g) 1128 to $1650 \mathrm{~nm}$

Figure 12. Equilibrium Spectrum for Test 62 data at 0.2 Torr. 


\section{V.D. Non-equilibrium Metric Spectral Radiance}

Figures 13 to 16 show the non-equilibrium metric applied to spectral radiance for the VUV through IR spectral regions. The non-equilibrium spectral radiance provides a meaningful way to spectrally present the data in non-equilibrium. Data is not presented for the highest speeds tested where no non-equilibrium pulse is observed, and for certain conditions in the IR spectral region, it is not possible to define the nonequilibrium metric due to the increased spatial smearing. As with the equilibrium spectral profiles, atomic radiation dominates in the VUV, Vis/NIR and IR spectral regions. However, in the UV/Vis spectral region, the radiation is dominated by molecular transitions.

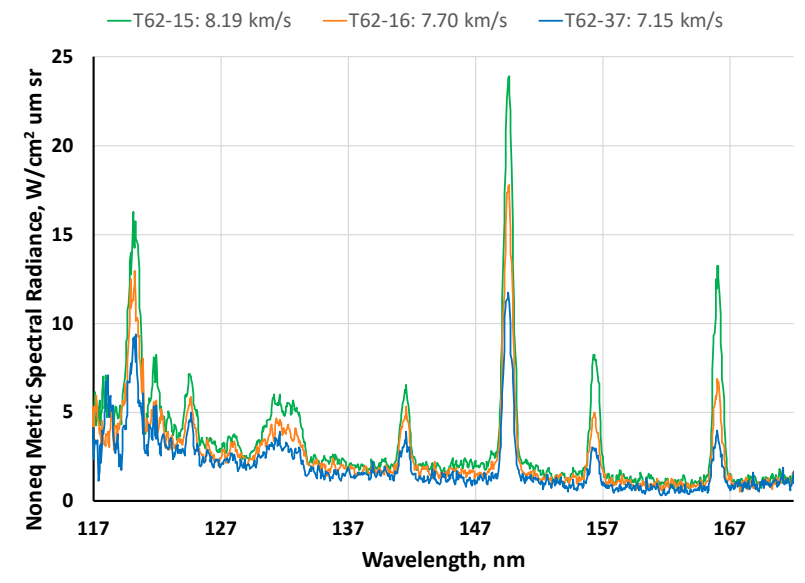

(a) Lower Speed: 130 to $172 \mathrm{~nm}$

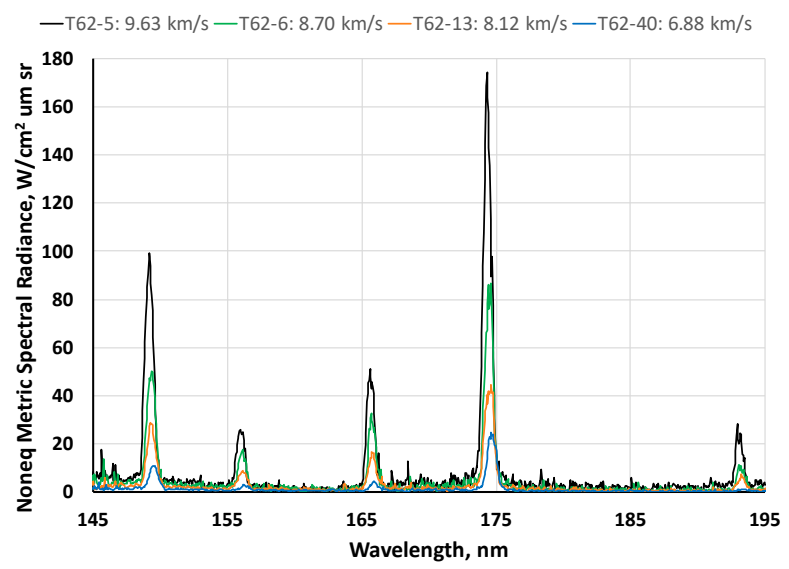

(c) Lower Speed: 145 to $195 \mathrm{~nm}$

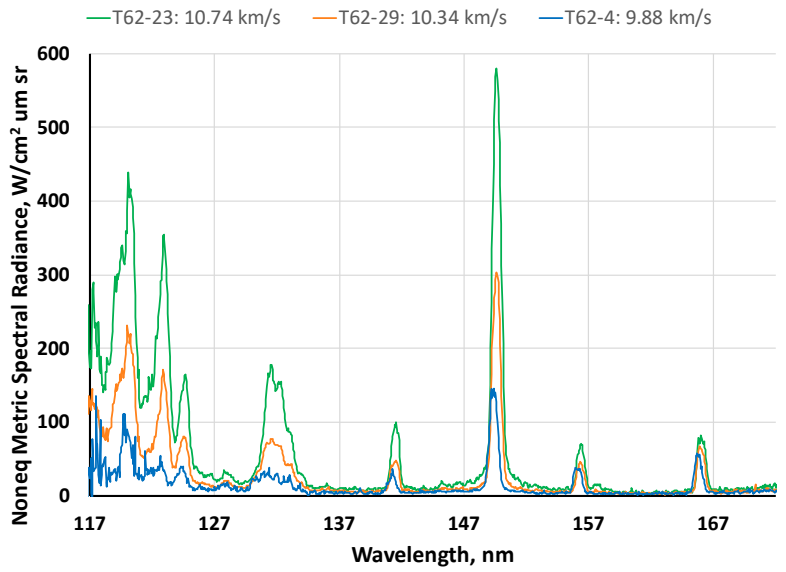

(b) Higher Speed: 130 to $172 \mathrm{~nm}$

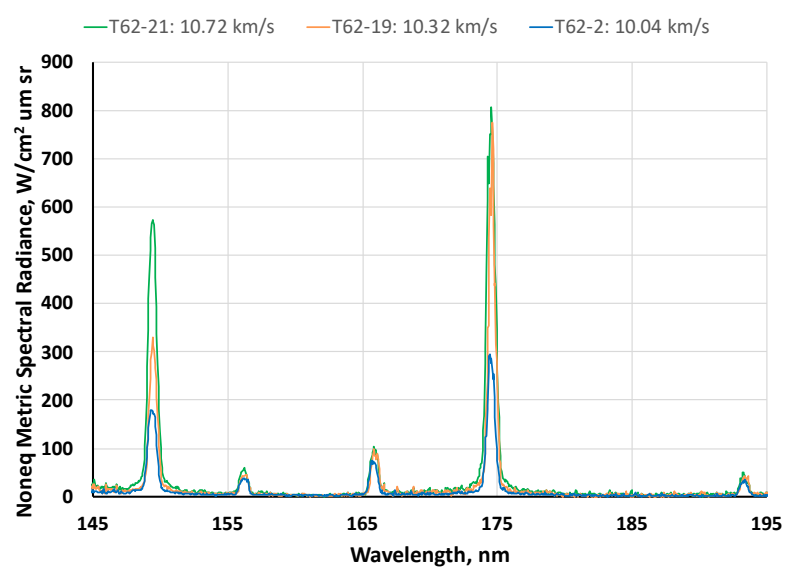

(d) Higher Speed: 145 to $195 \mathrm{~nm}$

Figure 13. Non-equilibrium Metric Spectrum for Test 62 data at 0.2 Torr in the VUV. 


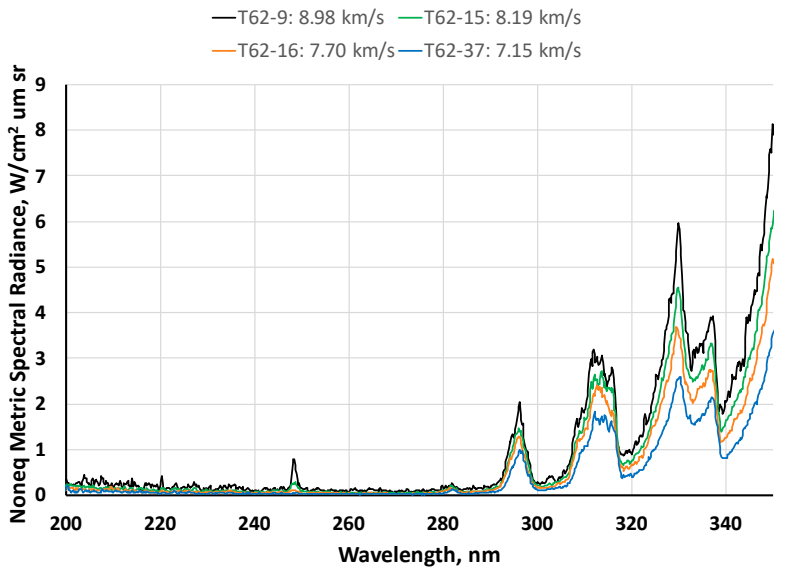

(a) Lower Speed: 200 to $350 \mathrm{~nm}$

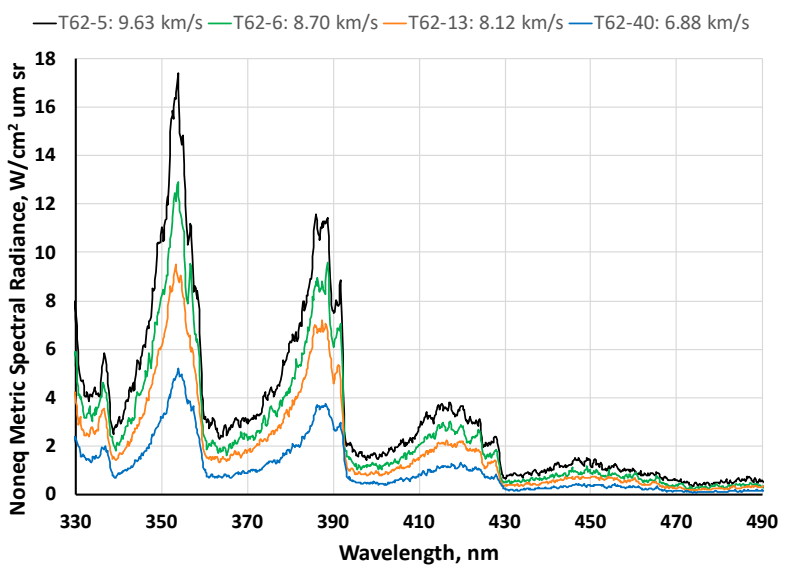

(c) Lower Speed: 330 to $490 \mathrm{~nm}$

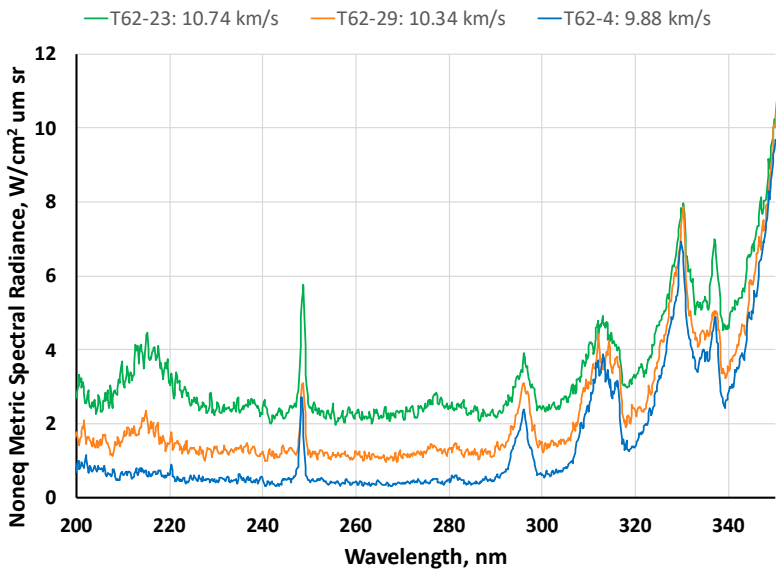

(b) Higher Speed: 200 to $350 \mathrm{~nm}$

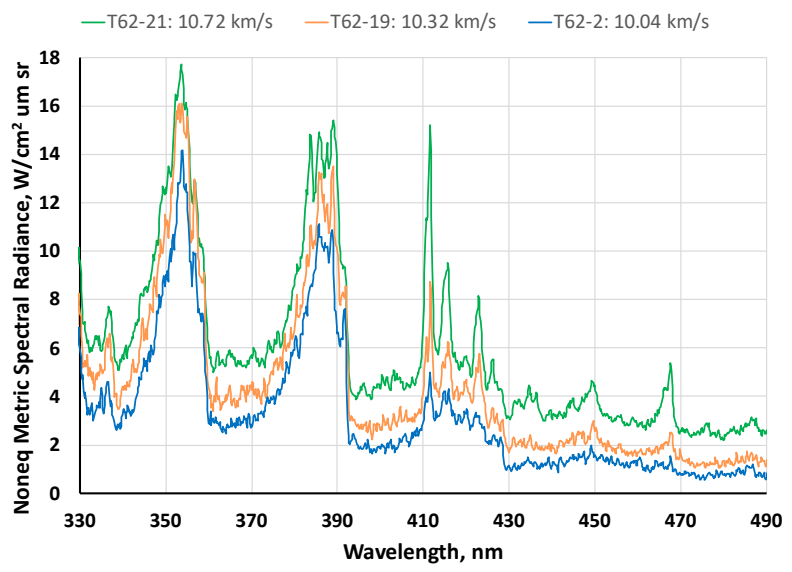

(d) Higher Speed: 330 to $490 \mathrm{~nm}$

Figure 14. Non-equilibrium Metric Spectrum for Test 62 data at 0.2 Torr in the UV/Vis.

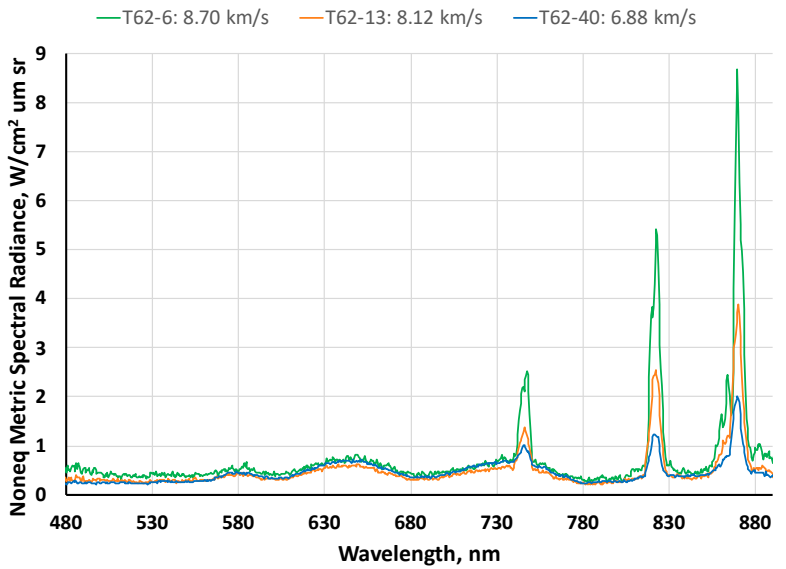

(a) Lower Speed: 480 to $890 \mathrm{~nm}$

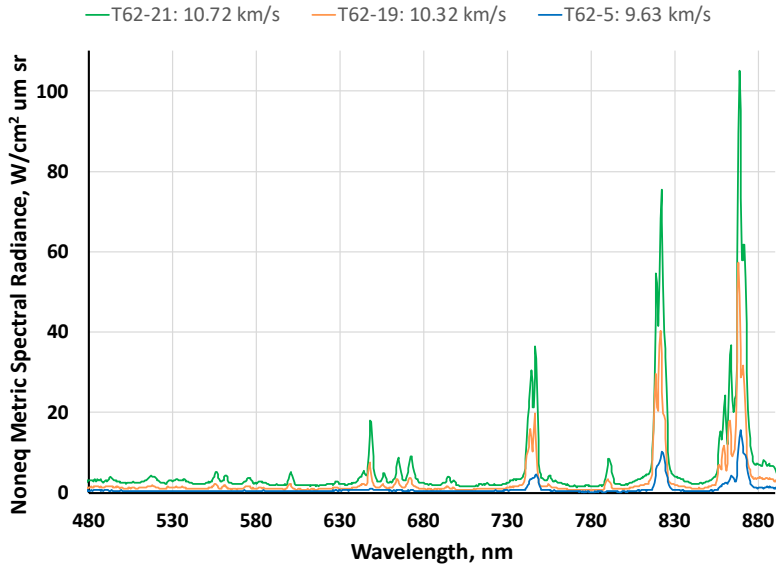

(b) Higher Speed: 480 to $890 \mathrm{~nm}$

Figure 15. Non-equilibrium Metric Spectrum for Test 62 data at 0.2 Torr in the Vis/NIR. 


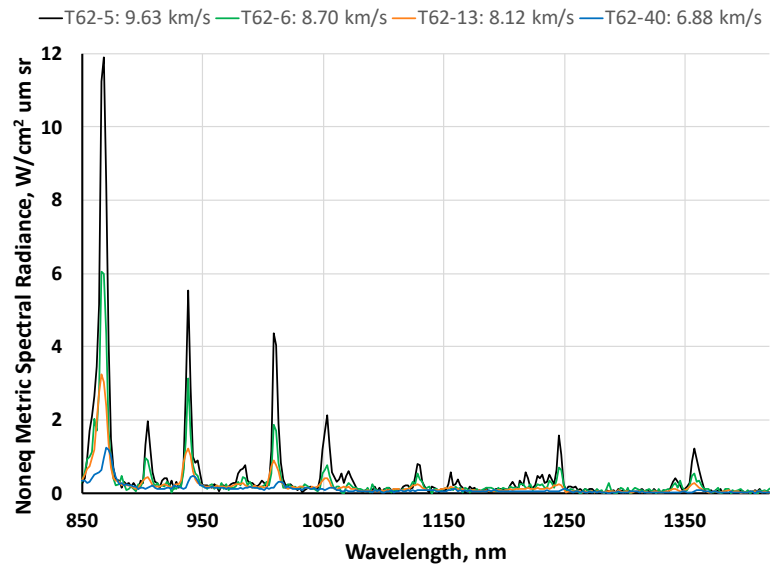

(a) 850 to $1420 \mathrm{~nm}$

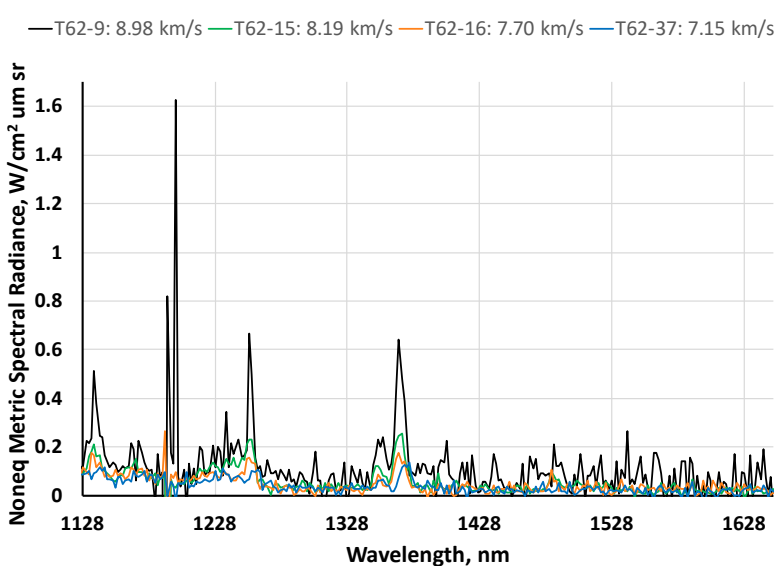

(b) 1128 to $1650 \mathrm{~nm}$

Figure 16. Non-equilibrium Metric Spectrum for Test 62 data at 0.2 Torr in the IR.

\section{Electron Number Density Analysis}

Seventeen of the tests were performed with high resolution measurement of the hydrogen Balmer- $\alpha$ line at $656 \mathrm{~nm}$. Hydrogen is present as an impurity in the shock tube, possibly as a product of water ( 100 ppm impurity) decomposition. The Balmer- $\alpha$ series lines show a high sensitivity to the Stark effect and thus these widths may be used to determine the electron density within the shock layer. The procedure for extracting electron density has been described previously. ${ }^{19}$ A Lorentzian profile is convolved with an experimentally determined instrument lineshape (see Appendix B) and the width obtained is converted to the electron density required to produce the broadening. Fifteen of the seventeen tests had useful test time, however no hydrogen features were detected at $7.2 \mathrm{~km} / \mathrm{s}$ and below. Velocities with measurable $\mathrm{H}$ radiation spanned $7.7-10.7 \mathrm{~km} / \mathrm{s}$. Fig. 17 shows the comparison of instrument lineshapes to the measured line in non-equilibrium at the low and high end of this range. For the $7.74 \mathrm{~km} / \mathrm{s}$ condition, the linewidth is slightly higher than the instrument shape, and the fit corresponds to an electron density of $3.7 \times 10^{14} \mathrm{~cm}^{3}$. At $10.74 \mathrm{~km} / \mathrm{s}$, the Stark broadening significantly exceeds the lineshape, corresponding to an electron density of $6.8 \times 10^{15} \mathrm{~cm}^{3}$.

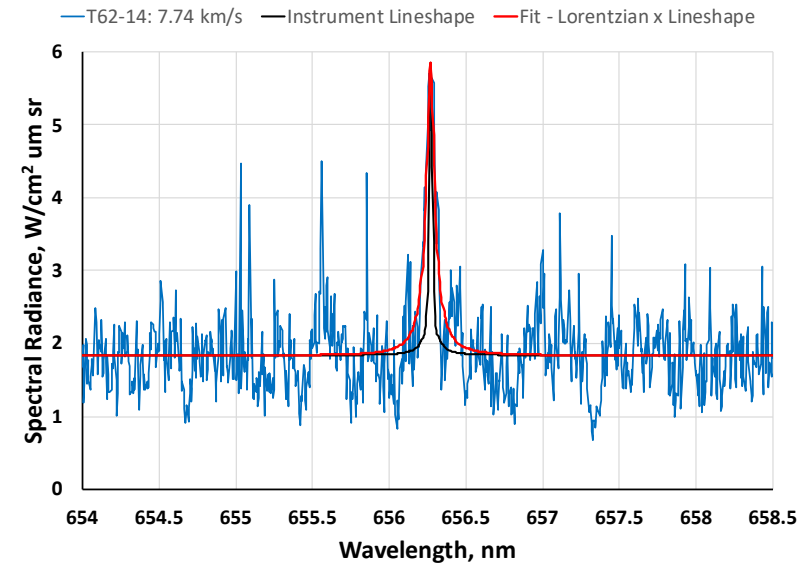

(a) $7.74 \mathrm{~km} / \mathrm{s}$

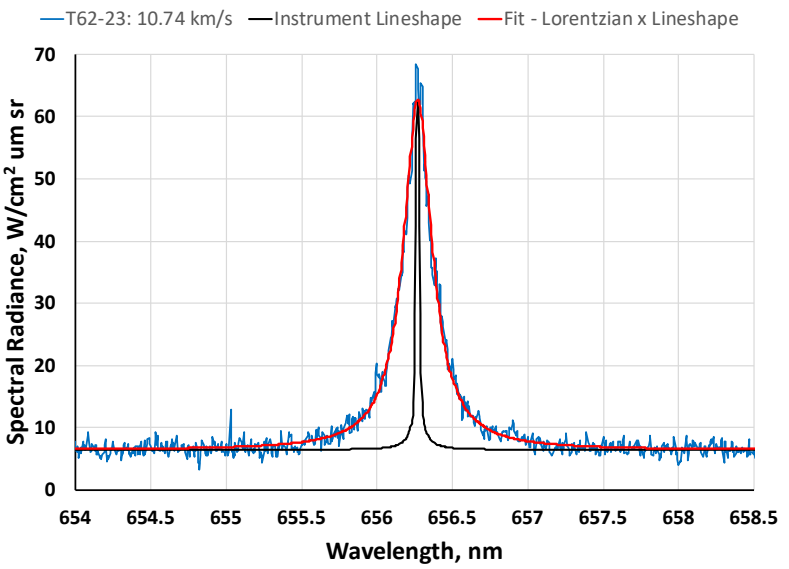

(b) $10.74 \mathrm{~km} / \mathrm{s}$

Figure 17. Measured non-equilibrium radiance from the $H-\alpha$ line. Also shown is the instrument lineshape and the convolution of a fit Lorentzian with instrument function.

Figure 18 shows the extracted electron density versus position for three of the experiments selected as benchmark data, and a lower speed test that showed relatively strong $\mathrm{H}-\alpha$ emission. Dashed lines on the plot show the equilibrium electron densities predicted by CEA. For the $7.7-8.2 \mathrm{~km} / \mathrm{s}$ conditions (not shown), the $\mathrm{H}-\alpha$ line could only be measured in the non-equilibrium zone, and the electron density fits 
exceed equilibrium by factors of several. It was not clear, however, whether this is indicative of an overshoot of the equilibrium electron number density or if it is due to the high level of noise in the fit at these low velocities. A relaxation toward equilibrium could not be discerned given the signal-to-noise levels. As shown in Fig. 18, near $9 \mathrm{~km} / \mathrm{s}$, the electron number density extracted is very noisy, but is generally larger than equilibrium. However, it is observed that the equilibrium condition is within the lower bound of the noise of the fit. At higher velocity conditions, the trend toward equilibrium is more apparent and the signal-tonoise improved. An exception to this is for the $9.9 \mathrm{~km} / \mathrm{s}$ condition, which exceeds its equilibrium value and does not appear to relax back toward equilibrium. This excess electron density has been seen in air tests at low velocity where measurements appear to diverge from equilibrium. ${ }^{19}$ This trend has been attributed to the effect of shock deceleration in the tube. At 10.4 and $10.7 \mathrm{~km} / \mathrm{s}$, the amplitude of the experimental noise encompasses the equilibrium values. The trend toward equilibrium is monotonic, with a characteristic distance on the order of $1 \mathrm{~cm}$. It is emphasized that this trend is not necessarily indicative of a characteristic time for ionization because the data is collected over a $1 \mu \mathrm{s}$ exposure time. At the velocities measured this corresponds to approximately $1 \mathrm{~cm}$ in spatial resolution loss. Further, the spatial resolution loss affects the radiative intensity; the electron density extracted from fitting the radiation profile will be impacted in a more complex manner. The better agreement with equilibrium at higher velocity is consistent with previous air testing, where it was observed that EAST conditions above $10 \mathrm{~km} / \mathrm{s}$ tended to show better equilibrium characteristics. ${ }^{17,19}$

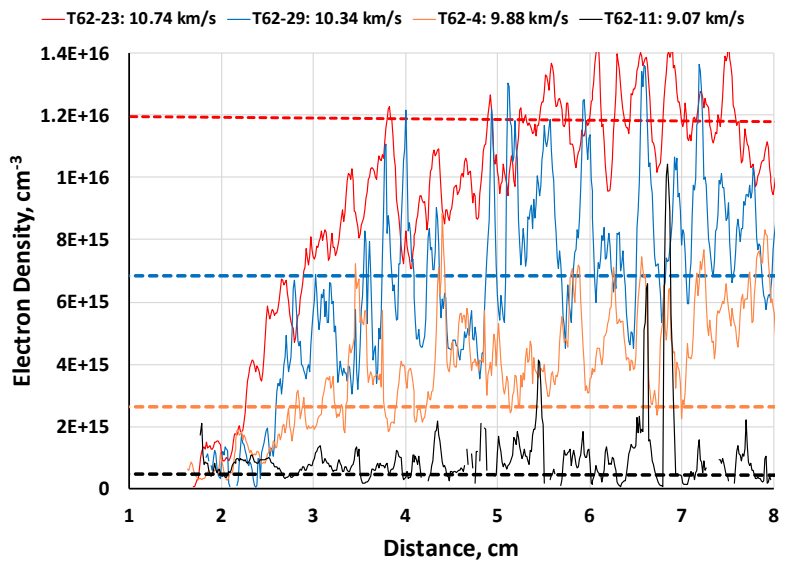

Figure 18. Extracted electron density versus position. The shock front is approximately at $2 \mathrm{~cm}$.

\section{Conclusion}

This paper presents the pure nitrogen experiments performed during the recent Test 62 campaign in the EAST facility. Experiments that showed good experimental characteristics, and are self-consistent for the non-equilibrium metric and equilibrium radiance, have been identified as benchmark datasets. Detailed information has been provided for these experiments so they may be recreated by simulation tools, used in validation studies, or replicated by other facilities. Spatial and spectral resolution data are included for correct interpretations for the level of agreement with simulations and the distance-time data for the shock traveling down the facility have also been included for the use in validation of future full facility CFD simulations. Comparisons of extracted electron number density agree well with equilibrium predictions at conditions above $10 \mathrm{~km} / \mathrm{s}$, and are higher than equilibrium for lower speeds. All of the EAST data is available at the following website: (https://data.nasa.gov/docs/datasets/aerothermodynamics/EAST/index.html).

\section{Acknowledgments}

The authors would like to thank NASA's Entry Systems Modeling project for their support of this work. Drs Aaron Brandis and Brett Cruden are supported through the NNA15BB15C contract between NASA Ames Research Center and AMA Inc. 


\section{References}

${ }^{1}$ Cruden, B. and Brandis, A., "Measurement and Prediction of Radiative Non-equilibrium for Air Shocks Between 7-9 km/s," 47th AIAA Thermophysics Conference, Denver, CO, 2017. AIAA 2017-4535.

${ }^{2}$ Brandis, A., Johnston, C., and Cruden, B., "Non-equilibrium Radiation for Earth Entry," 46th AIAA Thermophysics Conference, Washington, D.C., 2016, AIAA-2016-3690.

${ }^{3}$ Johnston, C. and Panesi, M., "Refinements to Afterbody Radiative Heating Simulations for Earth Entry," 46th AIAA Thermophysics Conference, Washington, D.C., 2016.

${ }^{4}$ Park, C., "Review of chemical-kinetic problems for future NASA missions, I. Earth entries," Journal of Thermophysics and Heat Transfer, Vol. 7, 1993, pp. 385-398.

${ }^{5}$ Panesi, M., Munafò, A., Magin, T. E., and Jaffe, R. L., "Nonequilibrium shock-heated nitrogen flows using a rovibrational state-to-state method," Phys. Rev. E, Vol. 90, Jul 2014, pp. 013009.

${ }^{6}$ Sahai, A., Lopez, B., Johnston, C. O., and Panesi, M., "Adaptive coarse graining method for energy transfer and dissociation kinetics of polyatomic species," The Journal of Chemical Physics, Vol. 147, No. 5, 2017, pp. 054107.

${ }^{7}$ Macdonald, R. L., Jaffe, R. L., Schwenke, D. W., and Panesi, M., "Construction of a coarse-grain quasi-classical trajectory method. I. Theory and application to $\mathrm{N}_{2}-\mathrm{N}_{2}$ system," The Journal of Chemical Physics, Vol. 148, No. 5, 2018 , pp. 054309.

${ }^{8}$ Macdonald, R. L., Grover, M. S., Schwartzentruber, T. E., and Panesi, M., "Construction of a coarse-grain quasi-classical trajectory method. II. Comparison against the direct molecular simulation method," The Journal of Chemical Physics, Vol. 148, No. 5, 2018, pp. 054310.

${ }^{9}$ Cruden, B., Martinez, R., Grinstead, J., and Olejniczak, J., "Simultaneous Vacuum-Ultraviolet Through Near-IR Absolute Radiation Measurement with Spatiotemporal Resolution in An Electric Arc Shock Tube," 41st AIAA Thermophysics Conference, San Antonio, Texas, 2009, AIAA-2009-4240.

${ }^{10}$ Cruden, B., "Absolute Radiation Measurements in Earth and Mars Entry Condition," Radiation and Gas-Surface Interaction Phenomena in High-Speed Re-Entry, Von Karman Institute Lecture Series, 2014.

${ }^{11}$ Whiting, E., Park, C., Yen, L., Arnold, J., and Paterson, J., "NEQAIR96, Nonequilibrium and Equilibrium Radiative Transport and Spectra Program: User's Manual," Technical Report NASA RP-1389, Ames Research Center, Moffett Field, Moffett Field, 1996.

${ }^{12}$ Kramida, A., Ralchenko, Y., Reader, J., and Team, N. A., "NIST Atomic Spectra Database, Version 5.0.0," physics.nist.gov/asd/, July 2012, last accessed July, 2012.

${ }^{13}$ Cunto, W., Mendoza, C., Ochsenbein, F., and Zeippen, C., "TOPbase at the CDS," Astronomy and Astrophysics, Vol. 275, Aug. 1993, pp. L5-L8, see also http://cdsweb.u-strasbg.fr/topbase/topbase.html.

${ }^{14}$ Tashkun, S. and Perevalov, V., "CDSD-4000: High-Resolution, High-Temperature Carbon Dioxide Spectroscopic Databank," Journal of Quantitative Spectroscopy and Radiative Transfer, Vol. 112, No. 9, 2011, pp. 1403-1410.

${ }^{15}$ Cruden, B. and Brandis, A., "Updates to the NEQAIR Radiation Solver," St. Andrews, Scotland, November 2014.

${ }^{16} \mathrm{McBride}, \mathrm{B}$. and Gordon, S., "Computer Program for Calculation of Complex Chemical Equilibrium Compositions and Applications I. Analysis," NASA RP-1311, NASA Glenn, October 1994.

${ }^{17}$ Brandis, A., Johnston, C., Cruden, B., Prabhu, D., and Bose, D., "Uncertainty Analysis and Validation of Radiation Measurements for Earth Re-Entry," Journal of Thermophysics and Heat Transfer, Vol. 29, No. 2, 2015, pp. $209-221$.

${ }^{18}$ Brandis, A., Johnston, C., Cruden, B., and Prabhu, D., "Investigation of Nonequilibrium Radiation for Mars Entry," 51st AIAA Aerospace Sciences Meeting, Grapevine, Texas, 2013, AIAA-2013-1055.

${ }^{19}$ Cruden, B., "Electron Density Measurement in Re-entry Shocks for Lunar Return," Journal of Thermophysics and Heat Transfer, Vol. 26, 2012, pp. 222-230. 


\section{A. Appendix - Spatial Resolution Function}

The spatial resolution function is given as the convolution of three different functions, as follows:

$$
S R F(x)=f_{\text {opt }}(x) \otimes f_{\text {cam }}(x) \otimes f_{\text {motion }}(x)
$$

Detailed forms of these functions are discussed in [2]. Here we use approximated forms of these functions defined as follows. For the optics up to $900 \mathrm{~nm}, f_{\text {opt }}$ is given by a triangular function:

$$
f_{\text {opt }}(\Delta x)=\frac{2}{d_{\text {opt }}} \max \left(1-\frac{2|\Delta x|}{d_{\text {opt }}}, 0\right)
$$

The camera function is given by the same function as the square root of a Voigt presented in Appendix B. The motion function is given by a square wave with width equal to the product of velocity and gating time.

$$
f_{\text {motion }}(\Delta x)=\left\{\begin{array}{lll}
d_{\text {gate }}^{-1} & |\Delta x|< & d_{\text {gate }} / 2 \\
0 & |\Delta x|>d_{\text {gate }} / 2
\end{array}\right.
$$

Values for $d_{g a t e}, d_{\text {opt }}$ and $w_{g}, w_{l}$ are given in Tables A1 - A3 for these three cameras below, in units of $\mathrm{cm}$.

Table A1. Spatial Resolution Functions for the VUV

\begin{tabular}{cccccc}
\hline \hline Shot Number & $\begin{array}{c}\text { Velocity, } \\
\mathrm{km} / \mathrm{s}\end{array}$ & $\begin{array}{c}d_{\text {opt }} \\
\mathrm{cm}\end{array}$ & $\begin{array}{c}w_{g} \\
\mathrm{~cm}\end{array}$ & $\begin{array}{c}w_{l} \\
\mathrm{~cm}\end{array}$ & $\begin{array}{c}d_{\text {gate }} \\
\mathrm{cm}\end{array}$ \\
\hline 2 & 10.04 & 0.041 & 0.039 & $5.52 \mathrm{E}-04$ & 0.502 \\
4 & 9.88 & 0.041 & 0.043 & $7.72 \mathrm{E}-04$ & 0.494 \\
5 & 9.63 & 0.041 & 0.048 & $4.02 \mathrm{E}-04$ & 0.481 \\
6 & 8.70 & 0.041 & 0.035 & $1.57 \mathrm{E}-03$ & 0.435 \\
9 & 8.98 & 0.041 & 0.046 & $5.87 \mathrm{E}-04$ & 0.449 \\
13 & 8.12 & 0.041 & 0.046 & $4.32 \mathrm{E}-04$ & 0.406 \\
15 & 8.19 & 0.041 & 0.046 & $4.32 \mathrm{E}-04$ & 0.819 \\
16 & 7.70 & 0.041 & 0.046 & $5.31 \mathrm{E}-04$ & 0.770 \\
19 & 10.32 & 0.041 & 0.015 & $1.47 \mathrm{E}-10$ & 0.516 \\
20 & 11.16 & 0.041 & 0.041 & $3.79 \mathrm{E}-04$ & 0.558 \\
21 & 10.72 & 0.041 & 0.037 & $1.71 \mathrm{E}-04$ & 0.268 \\
23 & 10.74 & 0.041 & 0.039 & $3.28 \mathrm{E}-04$ & 0.268 \\
29 & 10.34 & 0.041 & 0.037 & $4.94 \mathrm{E}-04$ & 0.517 \\
37 & 7.15 & 0.041 & 0.037 & $4.94 \mathrm{E}-04$ & 0.715 \\
40 & 6.88 & 0.041 & 0.037 & $4.94 \mathrm{E}-04$ & 0.688 \\
41 & 6.20 & 0.041 & 0.037 & $4.94 \mathrm{E}-04$ & 0.620 \\
42 & 5.94 & 0.041 & 0.037 & $4.94 \mathrm{E}-04$ & 0.594 \\
\hline \hline
\end{tabular}


Table A2. Spatial Resolution Functions for the UV/Vis

\begin{tabular}{cccccc}
\hline \hline Shot Number & $\begin{array}{c}\text { Velocity, } \\
\mathrm{km} / \mathrm{s}\end{array}$ & $\begin{array}{c}d_{\text {opt }} \\
\mathrm{cm}\end{array}$ & $\begin{array}{c}w_{g} \\
\mathrm{~cm}\end{array}$ & $\begin{array}{c}w_{l} \\
\mathrm{~cm}\end{array}$ & $\begin{array}{c}d_{\text {gate }} \\
\mathrm{cm}\end{array}$ \\
\hline 2 & 10.04 & 0.041 & 0.111 & $1.59 \mathrm{E}-03$ & 0.251 \\
4 & 9.88 & 0.041 & 0.111 & $1.59 \mathrm{E}-03$ & 0.247 \\
5 & 9.63 & 0.041 & 0.122 & $1.74 \mathrm{E}-03$ & 0.241 \\
6 & 8.7 & 0.041 & 0.111 & $1.26 \mathrm{E}-03$ & 0.218 \\
9 & 8.98 & 0.041 & 0.112 & $1.55 \mathrm{E}-03$ & 0.225 \\
13 & 8.12 & 0.041 & 0.110 & $2.16 \mathrm{E}-03$ & 0.203 \\
15 & 8.19 & 0.041 & 0.110 & $2.16 \mathrm{E}-03$ & 0.410 \\
16 & 7.7 & 0.041 & 0.101 & $5.75 \mathrm{E}-04$ & 0.385 \\
19 & 10.32 & 0.041 & 0.104 & $2.22 \mathrm{E}-03$ & 0.258 \\
20 & 11.16 & 0.041 & 0.120 & $1.53 \mathrm{E}-03$ & 0.279 \\
21 & 10.72 & 0.041 & 0.117 & $1.83 \mathrm{E}-03$ & 0.268 \\
23 & 10.74 & 0.041 & 0.091 & $2.36 \mathrm{E}-03$ & 0.268 \\
29 & 10.34 & 0.041 & 0.087 & $5.87 \mathrm{E}-03$ & 0.258 \\
37 & 7.15 & 0.041 & 0.087 & $5.87 \mathrm{E}-03$ & 0.357 \\
40 & 6.88 & 0.041 & 0.087 & $5.87 \mathrm{E}-03$ & 0.172 \\
41 & 6.2 & 0.041 & 0.087 & $5.87 \mathrm{E}-03$ & 0.155 \\
42 & 5.94 & 0.041 & 0.087 & $5.87 \mathrm{E}-03$ & 0.297 \\
\hline \hline
\end{tabular}

Table A3. Spatial Resolution Functions for the Vis/NIR

\begin{tabular}{cccccc}
\hline \hline Shot Number & $\begin{array}{c}\text { Velocity, } \\
\mathrm{km} / \mathrm{s}\end{array}$ & $\begin{array}{c}d_{\text {opt }} \\
\mathrm{cm}\end{array}$ & $\begin{array}{c}w_{g} \\
\mathrm{~cm}\end{array}$ & $\begin{array}{c}w_{l} \\
\mathrm{~cm}\end{array}$ & $\begin{array}{c}d_{\text {gate }} \\
\mathrm{cm}\end{array}$ \\
\hline 2 & 10.04 & 0.041 & 0.036 & $7.22 \mathrm{E}-03$ & 0.201 \\
4 & 9.88 & 0.041 & 0.027 & $6.11 \mathrm{E}-03$ & 0.988 \\
5 & 9.63 & 0.041 & 0.033 & $4.96 \mathrm{E}-03$ & 0.193 \\
6 & 8.7 & 0.041 & 0.048 & $5.98 \mathrm{E}-03$ & 0.174 \\
9 & 8.98 & 0.041 & 0.026 & $5.88 \mathrm{E}-03$ & 0.898 \\
13 & 8.12 & 0.041 & 0.032 & $4.52 \mathrm{E}-03$ & 0.162 \\
15 & 8.19 & 0.041 & 0.020 & $6.37 \mathrm{E}-03$ & 0.819 \\
16 & 7.7 & 0.041 & 0.025 & $5.56 \mathrm{E}-03$ & 0.770 \\
19 & 10.32 & 0.041 & 0.019 & $3.03 \mathrm{E}-03$ & 0.206 \\
20 & 11.16 & 0.041 & 0.034 & $4.70 \mathrm{E}-03$ & 0.223 \\
21 & 10.72 & 0.041 & 0.032 & $4.67 \mathrm{E}-03$ & 0.214 \\
23 & 10.74 & 0.041 & 0.024 & $5.68 \mathrm{E}-03$ & 1.074 \\
29 & 10.34 & 0.041 & 0.024 & $5.65 \mathrm{E}-03$ & 1.034 \\
37 & 7.15 & 0.041 & 0.024 & $5.65 \mathrm{E}-03$ & 0.715 \\
40 & 6.88 & 0.041 & 0.024 & $5.65 \mathrm{E}-03$ & 0.344 \\
41 & 6.2 & 0.041 & 0.024 & $5.65 \mathrm{E}-03$ & 0.310 \\
42 & 5.94 & 0.041 & 0.024 & $5.65 \mathrm{E}-03$ & 0.594 \\
\hline \hline
\end{tabular}

19 of 25 
For the infrared camera, the optical function is taken to be a trapezoid :

$$
f_{o p t}(\Delta x)=\frac{2 d_{o p t, 2}}{d_{o p t, 2}^{2}-d_{o p t, 1}^{2}} \min \left(1-\frac{d_{o p t, 1}}{d_{o p t, 2}}, \max \left(1-\frac{2|\Delta x|}{d_{o p t, 2}}\right), 0\right)
$$

where $d_{o p t, 1}$ and $d_{o p t, 2}$ are the two bases of the trapezoid. The camera shape is taken to be a Gaussian with half-width $w_{g}$. Values of $d_{o p t}, d_{\text {gate }}$ and $w_{g}$ for the infrared cameras are given in Table A4.

Table A4. Spatial Resolution Functions for the IR

\begin{tabular}{cccccc}
\hline Shot Number & $\begin{array}{c}\text { Velocity, } \\
\mathrm{km} / \mathrm{s}\end{array}$ & $\begin{array}{c}d_{\text {opt } 1} \\
\mathrm{~cm}\end{array}$ & $\begin{array}{c}d_{\text {opt } 2} \\
\mathrm{~cm}\end{array}$ & $\begin{array}{c}w_{g} \\
\mathrm{~cm}\end{array}$ & $\begin{array}{c}d_{\text {gate }} \\
\mathrm{cm}\end{array}$ \\
\hline 2 & 10.04 & 0.313 & 0.128 & 0.094 & 0.984 \\
4 & 9.88 & 0.313 & 0.128 & 0.097 & 0.968 \\
5 & 9.63 & 0.313 & 0.128 & 0.088 & 0.944 \\
6 & 8.7 & 0.313 & 0.128 & 0.092 & 0.853 \\
9 & 8.98 & 0.313 & 0.128 & 0.080 & 0.880 \\
13 & 8.12 & 0.313 & 0.128 & 0.076 & 0.795 \\
15 & 8.19 & 0.313 & 0.128 & 0.079 & 0.803 \\
16 & 7.7 & 0.313 & 0.128 & 0.079 & 0.754 \\
19 & 10.32 & 0.313 & 0.128 & 0.094 & 1.011 \\
20 & 11.16 & 0.313 & 0.128 & 0.081 & 1.094 \\
21 & 10.72 & 0.313 & 0.128 & 0.090 & 1.050 \\
23 & 10.74 & 0.313 & 0.128 & 0.111 & 1.052 \\
29 & 10.34 & 0.313 & 0.128 & 0.086 & 1.013 \\
37 & 7.15 & 0.313 & 0.128 & 0.086 & 0.700 \\
40 & 6.88 & 0.313 & 0.128 & 0.086 & 0.674 \\
41 & 6.2 & 0.313 & 0.128 & 0.086 & 0.607 \\
42 & 5.94 & 0.313 & 0.128 & 0.086 & 0.583 \\
\hline \hline
\end{tabular}




\section{B. Appendix - Spectral Resolution Function}

Details for the instrument line shape (ILS), also known as spectral resolution function, are given here. There are two lineshapes described. For measurements below $500 \mathrm{~nm}$, the parameters are for the square root of a Voigt function, where:

$$
I L S_{1}(\Delta \lambda)=\frac{\left[V\left(\Delta \lambda ; w_{l}, w_{g}\right)\right]^{0.5}}{2 \int_{0}^{\infty}\left[V\left(x ; w_{l}, w_{g}\right)\right]^{0.5} \mathrm{~d} x}
$$

where the Voigt function:

$$
V\left(\Delta \lambda ; w_{g}, w_{g}\right)=L\left(\Delta \lambda ; w_{l}\right) \otimes G\left(\Delta \lambda ; w_{g}\right)
$$

is the convolution of Lorentzian and Gaussian functions. The Lorentzian and Gaussian functions are given as:

$$
\begin{gathered}
L\left(\Delta \lambda ; w_{l}\right)=\frac{\pi^{-1}}{\left(\frac{\Delta \lambda}{w_{l}}\right)^{2}+1} \\
G\left(\Delta \lambda ; w_{g}\right)=\frac{1}{w_{g}} \sqrt{\frac{\ln 2}{\pi}} \exp \left[-\ln 2\left(\frac{\Delta \lambda}{w_{g}}\right)^{2}\right]
\end{gathered}
$$

where $w_{g}$ and $w_{l}$ are the half-widths at half-maximum of a Gaussian and Lorentzian respectively. Note that the forms of $\mathrm{L}$ and $\mathrm{G}$ are normalized such that their integral is unity. The denominator in Eq. B1 indicates that the ILS must be similarly normalized. This is not expressed analytically, and must be done numerically.

Above $500 \mathrm{~nm}$, the second form of the ILS is preferred. This function is a linear combination of Lorentzian and Gaussian functions. The function normalization is included in the following formula:

$$
I L S_{2}(\Delta \lambda)=\frac{G\left(\Delta \lambda ; w_{g}\right)+10^{r} L\left(\Delta \lambda ; w_{l}\right)}{1+10^{r}}
$$

In the infrared, it is often not possible to fit a Lorentzian component. In this case, a single Gaussian is used for the ILS and no value is given for $w_{l}$ or $r$ in the table.

The appropriate lineshape number for each shot is given in Table B1 and the corresponding parameters entering into the above expressions are given in Table B2, in units of nanometers. Note that NEQAIR uses full widths in angstroms, so the presented values would need to be multiplied by 20 . 
Table B1. Instrument Lineshape Look Up Information.

\begin{tabular}{cccccc}
\hline \hline $\begin{array}{c}\text { Shot } \\
\#\end{array}$ & $\begin{array}{c}\text { Shock Speed, } \\
\mathbf{k m} / \mathbf{s}\end{array}$ & VUV & UV/Vis & Vis/NIR & IR \\
\hline 42 & 5.94 & 3 & 3 & 3 & 2 \\
41 & 6.20 & 3 & 3 & 3 & 2 \\
40 & 6.88 & 3 & 3 & 3 & 2 \\
37 & 7.15 & 3 & 3 & 5 & 2 \\
16 & 7.70 & 3 & 3 & 5 & 2 \\
13 & 8.12 & 3 & 3 & 3 & 2 \\
15 & 8.19 & 3 & 3 & 5 & 2 \\
6 & 8.70 & 2 & 2 & 2 & 1 \\
9 & 8.98 & 2 & 2 & 4 & 1 \\
5 & 9.63 & 2 & 2 & 2 & 1 \\
4 & 9.88 & 2 & 2 & 4 & 1 \\
2 & 10.04 & 2 & 1 & 1 & 1 \\
19 & 10.32 & 1 & 1 & 1 & 1 \\
29 & 10.34 & 2 & 2 & 4 & 1 \\
21 & 10.72 & 2 & 2 & 1 & 3 \\
23 & 10.74 & 2 & 2 & 4 & 3 \\
20 & 11.16 & 2 & 2 & 1 & 1 \\
\hline \hline
\end{tabular}

Table B2. Instrument Lineshape Data

\begin{tabular}{ccccccc}
\hline \hline Camera & Lineshape & \multicolumn{2}{c}{ Square Root Voigt } & \multicolumn{3}{c}{ Gauss+Lorentzian } \\
& No. & $\mathbf{w}_{\mathbf{g}}, \mathbf{n m}$ & $\mathbf{w}_{\mathbf{l}}, \mathbf{n m}$ & $\mathbf{w}_{\mathbf{g}}, \mathbf{n m}$ & $\mathbf{w}_{\mathbf{l}}, \mathbf{n m}$ & $\mathbf{r}$ \\
\hline VUV & 1 & 0.192 & 0.006 & 0.270 & 0.270 & -0.130 \\
& 2 & 0.198 & 0.006 & 0.270 & 0.270 & -0.130 \\
& 3 & 0.207 & 0.007 & 0.280 & 0.360 & -0.450 \\
UV/Vis & 1 & 0.222 & 0.024 & 0.320 & 0.304 & 0.559 \\
& 2 & 0.3071 & 0.0241 & 0.4299 & 0.4167 & 0.4140 \\
& 3 & 0.4221 & 0.0223 & 0.6018 & 5.5024 & -1.3966 \\
Vis/NIR & 1 & 0.574 & 0.024 & 0.811 & 6.009 & -1.387 \\
& 2 & 0.796 & 0.024 & 1.121 & 9.469 & -1.498 \\
& 3 & 1.205 & 0.030 & 1.690 & 13.838 & -1.529 \\
& 4 & 0.008 & 0.001 & 0.012 & 0.046 & -0.815 \\
& 5 & 0.012 & 0.003 & 0.015 & 0.037 & -0.317 \\
IR & 1 & 1.183 & 0.055 & 2.335 & 0.868 & 0.425 \\
& 2 & 2.127 & 0.001 & 3.034 & - & - \\
& 3 & 1.179 & 0.046 & 2.316 & 0.789 & 0.469 \\
\hline \hline
\end{tabular}




\section{Appendix - Shock Time of Arrival Data}

The shock time of arrival data obtained with PCB's for all of the benchmark EAST Test 62 datasets is presented in Tables $\mathrm{C} 1$ and $\mathrm{C} 2$. The way this data is interpreted at the EAST facility is take adjacent finite differences of the time of arrival data for the early transducers when there is significant distances between each sensor. The density of the sensors is greatly increased approaching and at the test section. This starts from $773.1 \mathrm{~cm}$ and these data are fit with a polynomial, and the derivative taken to obtain shock speed as a function of distance. The quoted shock speed for each test is at the $789.0 \mathrm{~cm}$ location, as this the optimal shock location when the camera's trigger. It is frequently noted that the level of shock deceleration increases at the test section, plausibly due to the increased number of ports and windows in this section of the facility. 


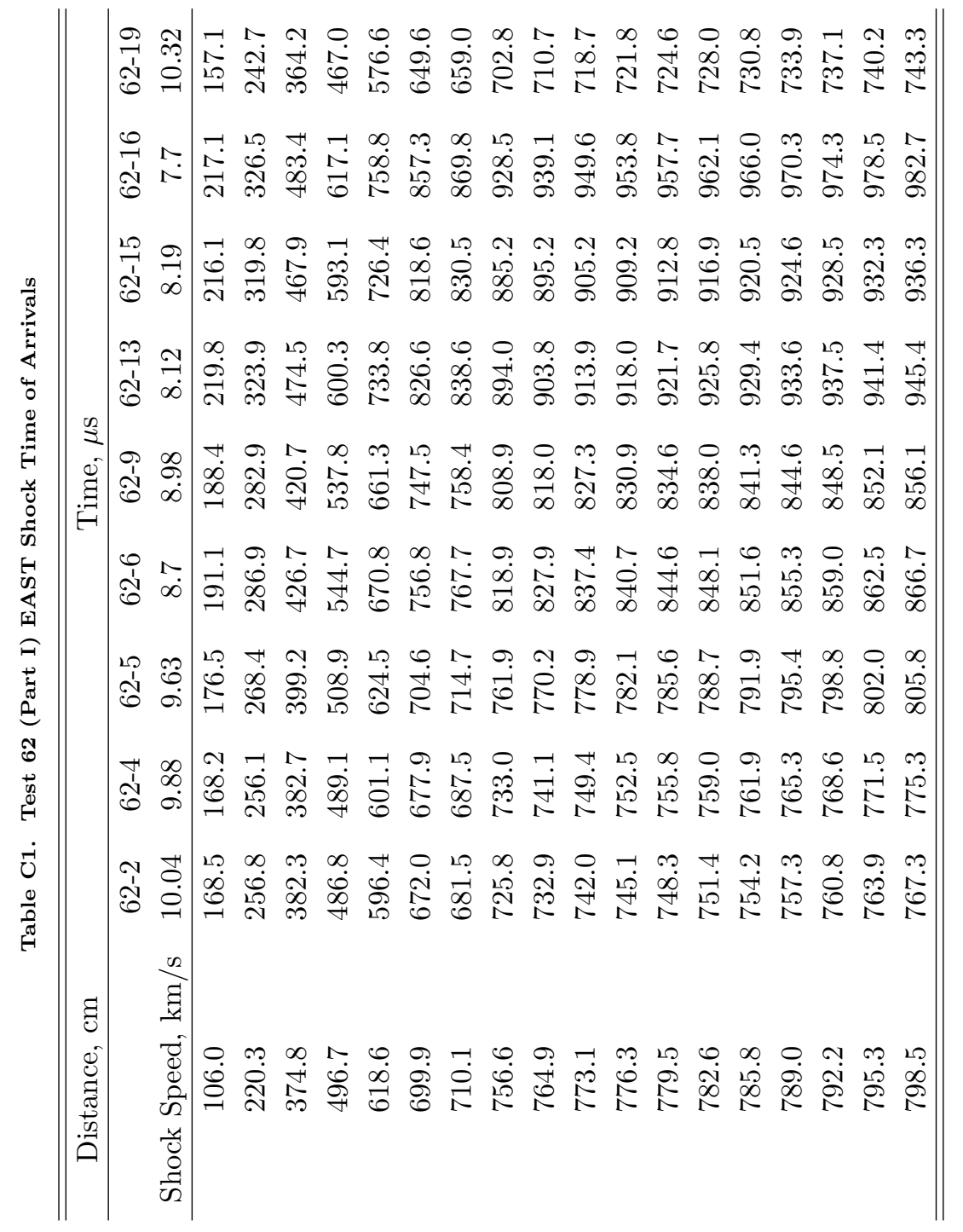

\section{4 of 25}




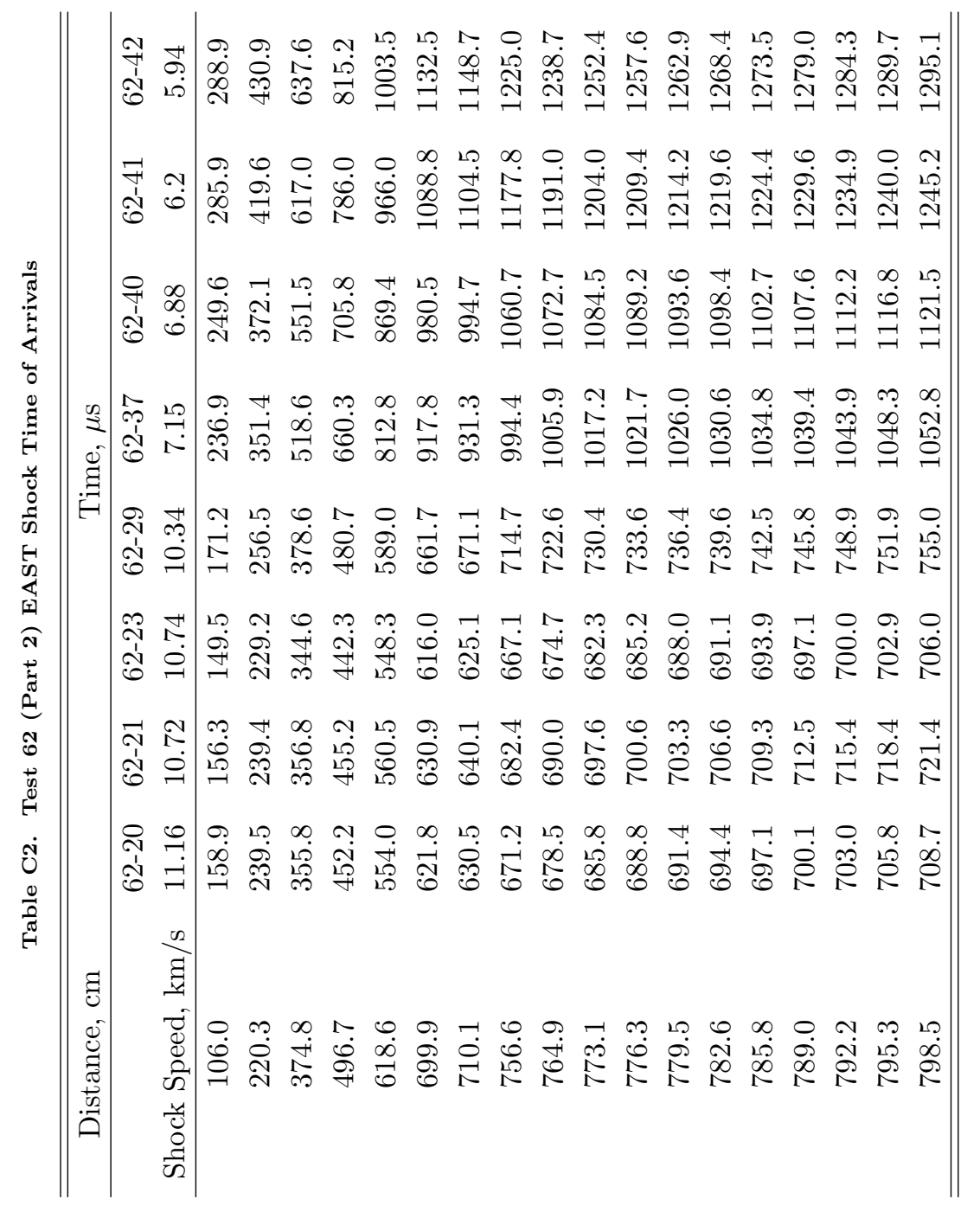

25 of 25 